\title{
Retrieval of temperature profiles from CHAMP for climate monitoring: intercomparison with Envisat MIPAS and GOMOS and different atmospheric analyses
}

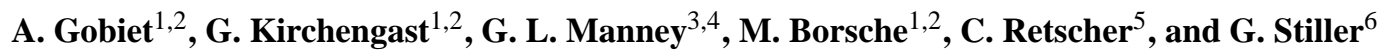 \\ ${ }^{1}$ Wegener Center for Climate and Global Change, University of Graz, Austria \\ ${ }^{2}$ Institute for Geophysics, Astrophysics, and Meteorology, University of Graz, Austria \\ ${ }^{3}$ Jet Propulsion Laboratory, California Institute of Technology, CA, USA \\ ${ }^{4}$ New Mexico Institute of Mining and Technology, NM, USA \\ ${ }^{5}$ ESA/ESRIN, Frascati, Italy \\ ${ }^{6}$ Institut für Meteorologie und Klimaforschung, Forschungszentrum Karlsruhe, Germany
}

Received: 13 December 2006 - Published in Atmos. Chem. Phys. Discuss.: 27 February 2007

Revised: 31 May 2007 - Accepted: 18 June 2007 - Published: 4 July 2007

\begin{abstract}
This study describes and evaluates a Global Navigation Satellite System (GNSS) radio occultation (RO) retrieval scheme particularly aimed at delivering bias-free atmospheric parameters for climate monitoring and research. The focus of the retrieval is on the sensible use of a priori information for careful high-altitude initialisation in order to maximise the usable altitude range. The RO retrieval scheme has been meanwhile applied to more than five years of data (September 2001 to present) from the German CHAllenging Minisatellite Payload for geoscientific research (CHAMP) satellite. In this study it was validated against various correlative datasets including the Michelson Interferometer for Passive Atmospheric Sounding (MIPAS) and the Global Ozone Monitoring for Occultation of Stars (GOMOS) sensors on Envisat, five different atmospheric analyses, and the operational CHAMP retrieval product from GeoForschungsZentrum (GFZ) Potsdam. In the global mean within 10 to $30 \mathrm{~km}$ altitude we find that the present validation observationally constrains the potential RO temperature bias to be $<0.2 \mathrm{~K}$. Latitudinally resolved analyses show biases to be observationally constrained to $<0.2-0.5 \mathrm{~K}$ up to $35 \mathrm{~km}$ in most cases, and up to $30 \mathrm{~km}$ in any case, even if severely biased (about $10 \mathrm{~K}$ or more) a priori information is used in the high altitude initialisation of the retrieval. No evidence is found for the $10-35 \mathrm{~km}$ altitude range of residual RO bias sources other than those potentially propagated downward from initialisation, indicating that the widely quoted RO promise of "unbiasedness and long-term stability due to intrinsic self-calibration" can indeed be realised given care in the data processing to strictly limit structural uncertainty.
\end{abstract}

Correspondence to: A. Gobiet

(andreas.gobiet@uni-graz.at)
The results thus reinforce that adequate high-altitude initialisation is crucial for accurate stratospheric RO retrievals. The common method of initialising, at some altitude in the upper stratosphere, the hydrostatic integral with an upper boundary temperature or pressure value derived from meteorological analyses is prone to introduce biases from the upper boundary down to below $25 \mathrm{~km}$. Also above 30 to $35 \mathrm{~km}$, GNSS RO delivers a considerable amount of observed information up to around $40 \mathrm{~km}$, which is particularly interesting for numerical weather prediction (NWP) systems, where direct assimilation of non-initialised observed RO bending angles (free of a priori) is thus the method of choice. The results underline the value of $\mathrm{RO}$ for climate applications.

\section{Introduction}

The Global Navigation Satellite System (GNSS) radio occultation (RO) technique (e.g., Kursinski et al., 1997) is an active satellite-to-satellite limb sounding concept using GNSS signals to probe the atmosphere. It provides atmospheric parameters like refractivity, geopotential height (or pressure), and temperature with high vertical resolution ( 0.5 to $1.5 \mathrm{~km})$, high accuracy $(<1 \mathrm{~K})$, long-term stability, virtual all-weather capability (insensitivity to clouds), and global coverage over an altitude range from the lower troposphere to the upper stratosphere showing best performance in the upper troposphere-lower stratosphere region ( 5 to $35 \mathrm{~km}$ ) (e.g., Steiner and Kirchengast, 2005). A key asset of the RO technique for climate applications is its traceability to the most reliable and accurate calibration standard available, the S.I. (Système International d'Unités) definition of the second

Published by Copernicus Publications on behalf of the European Geosciences Union. 
(Leroy et al., 2006), which enables long-term stability without need for instrument or satellite inter-calibration, usually termed "self-calibration" property of RO.

Owing to these characteristics the RO technique is a unique new data source for atmospheric and climate sciences. Particularly the high vertical resolution and accuracy in regions where so far predominantly rather low vertical resolution satellite-based data from nadir looking instruments are available (e.g., over remote oceanic areas and in polar regions) opens new possibilities for the evaluation and advancement of analyses and forecasts of numerical weather prediction (NWP) systems (e.g., Gobiet et al., 2005; Healy et al., 2005; Borsche et al., 2007; Healy and Thépaut, 2006) and for stratospheric process studies (e.g., Alfred et al., 2006). In addition, its "self-calibrating" nature makes it ideal for providing benchmark datasets for the validation of other remote sensing systems (Schroeder et al., 2003; Wang et al., 2004, 2005; Steiner et al., 2007 ${ }^{1}$ ) the evaluation and advancement of climate models (Goody et al., 1998; Leroy et al., 2006) and for climate monitoring in general (Foelsche et al., 2005, 2006).

Evaluation studies showed that RO temperatures are generally derived with an accuracy of better than $1 \mathrm{~K}$ (e.g., Hajj et al., 2002; Wickert et al., 2004; Steiner et al., 2004) though it has also been found that RO retrieval results of major processing centres show, compared to other remote sensing instruments, radiosondes, and amongst themselves, biases exceeding $1 \mathrm{~K}$ above $25 \mathrm{~km}$ (e.g., Wang et al., 2004; Wickert et al., 2004; von Engeln, 2006) which is mainly due to the methodology of integrating a priori information in the highaltitude initialisation of the retrieval process as will be discussed in this study. Biases induced by downward propagated a priori information are a particular concern for climate applications like, e.g., long-term trend studies, since a priori data (often meteorological analyses) are on one hand particularly prone to model errors due to sparse observational data at high altitudes, and on the other hand they are far from long-term stable due to frequent model, observational data, and data assimilation system changes and improvements. Systematic changes in the a priori information could therefore severely degrade the basic self-calibrating nature of RO measurements by introducing artificial trends down into the lower stratosphere below 30 to $35 \mathrm{~km}$. It is thus of high importance to maximise the altitude range of unbiased RO data upwards by as adequate data processing as possible (Gobiet and Kirchengast, 2004; Steiner and Kirchengast, 2005).

This study proceeds as follows: In Sect. 2 the developed operational RO retrieval scheme for data from the German CHAllenging Minisatellite Payload for geoscientific research (CHAMP) satellite, with particular focus on the requirements

\footnotetext{
${ }^{1}$ Steiner, A. K., Kirchengast, G., Borsche, M., Foelsche, U., and Schoengassner, T.: A multi-year comparison of lower stratospheric temperatures from CHAMP radio occultation data with MSU/AMSU records, J. Geophys. Res., revised, 2007.
}

of climate monitoring and bias minimisation at high altitudes, is described. The subsequent validation of the performance of this retrieval scheme in Sects. 3 and 4 is based on a broad range of correlative data sources including Envisat limb sounding instruments, various NWP analyses, and a different RO retrieval scheme. This provides a reliable basis for the summary and conclusions in Sect. 5, where the biases (upper bounds) are summarised based on the intercomparison results and the conclusions are drawn.

\section{Retrieval of RO temperature profiles}

The presented retrieval scheme (CHAMPCLIM Retrieval, CCR) aims at optimal exploitation of RO data for climate research with a particular focus on avoidance of systematic errors and eventual drifts by minimising the influence of a priori information used for initialising the retrieval at high altitudes (upper stratosphere upwards) as a potential source of temporarily inhomogeneous biases. A related aim is to minimise the amount of background information entering the retrieval process and to make the influence of the background information traceable. Based on these measures, CCR aims to extend the altitude range of reliable, accurate retrieval results (currently up to about $25 \mathrm{~km}$; see Sect. 4; Wang et al., 2004; Wickert et al., 2004; von Engeln, 2006) towards the upper stratosphere (up to about $35 \mathrm{~km}$ ). The development of the algorithmic basis and careful performance assessment via end-to-end simulation studies by Gobiet and Kirchengast (2004) and Steiner and Kirchengast (2005) have demonstrated that this improvement potential exists.

The described CCR scheme is currently applied to data from the first satellite providing RO measurements on a longer term, CHAMP (Wickert et al., 2001, 2004), and is the basis for the first RO-based multi-year temperature climatology, which has been developed in the framework of the CHAMPCLIM project (Foelsche et al., 2005, 2006), a cooperation of the Wegener Center, University of Graz, Austria and the GeoForschungsZentrum (GFZ) Potsdam, Germany.

\subsection{Basic RO retrieval}

The basic CCR scheme developed and applied here is a socalled dry air retrieval scheme. It is briefly summarised here; a detailed treatment of basic RO retrieval techniques is given in a review-type manner by Kursinski et al. (1997) and Hajj et al. (2002). The primary observables of RO measurements are phase delays of GNSS signals, i.e., the consequences of deceleration of electromagnetic wave's phase velocities by the atmosphere. Doppler shifts and subsequently the total bending angle $(\alpha)$ and impact parameter $(a)$ of an occultation ray are deduced from phase delays involving transmitter and receiver orbit data using geometric optics and local spherical symmetry assumptions. Using GNSS signals from the Global Positioning System (GPS), two different carrier 
frequencies are available, which allow to remove large parts of the dispersive ionospheric contribution to the signal by linear combination of bending angles of both frequencies (Vorob'ev and Krasil'nikova, 1994). The refractive index of the neutral atmosphere $(n)$ can then be derived via the inverse Abel transform (Fjeldbo et al., 1971),

$n(a)=\exp \left[\frac{1}{\pi} \int_{a}^{\infty} \frac{\alpha\left(a^{\prime}\right)}{\sqrt{a^{\prime 2}-a^{2}}} d a^{\prime}\right]$,

from which refractivity as a function of height, $N(z)$, is obtained via the relation $N(a)=10^{6}(n(a)-1)$ and $z(a)=a / n(a)-R_{C} . R_{C}$ is the radius of curvature of the Earth along the occultation plane (Syndergaard, 1998). Refractivity is related to atmospheric pressure $(p)$, temperature $(T)$, and the partial pressure of water vapour $\left(p_{w}\right)$ via

$N=k_{1} \frac{p}{T}+k_{2} \frac{p_{w}}{T^{2}}$

where $k_{1}$ and $k_{2}$ are constants $\left(k_{1}=77.60 \mathrm{~K} / \mathrm{hPa}\right.$, $k_{2}=3.73 \cdot 10^{5} \mathrm{~K}^{2} / \mathrm{hPa}$; e.g., Bevis et al., 1994).

Using the refractivity equation (Eq. 2), the hydrostatic equation, the equation of state, and the gravity formula, atmospheric parameters can be derived. For example, dry pressure $p_{d}(z)$ (which equals the total air pressure $p(z)$ if humidity can be neglected, i.e., above the middle troposphere) is obtained via hydrostatic integration,

$p_{d}(z)=\frac{M_{d}}{k_{1} R} \int_{z}^{\infty} g\left(z^{\prime}\right) N\left(z^{\prime}\right) d z^{\prime}$,

where $R$ is the universal gas constant $\left(8.3145 \cdot 10^{3}\right.$ $\left.\mathrm{JK}^{-1} \mathrm{~kg}^{-1}\right), M_{d}$ is the molar mass of dry air $(28.964 \mathrm{~kg}$ $\mathrm{kmol}^{-1}$ ), and $g\left(z^{\prime}\right)$ is the acceleration of gravity. Dry temperature (which, similarly to dry pressure, absorbs the effect of water vapour) is then obtained as

$T_{d}(z)=k_{1} \frac{p_{d}(z)}{N(z)}$.

We note that if the air is sufficiently moist so that humidity cannot be neglected, as is typically the case in the lower and middle troposphere, then temperature and water vapour can only be retrieved separately if a priori information on at least one of the two parameters is available (e.g., Kursinski et al., 1997; Healy and Eyre, 2000). This moist air retrieval, a part of the CCR follow-on retrieval scheme at the Wegener Center, is not further treated here since the lower and middle troposphere is below our analysis domain limited to above $10 \mathrm{~km}$ in this study. We thus exclusively regard dry temperature as defined above, assuming the contribution of the water vapour to be negligible, which is generally a very good assumption above $10 \mathrm{~km}$ (e.g., Gobiet, 2005).
2.2 High-altitude initialisation and statistical optimisation

The integrate formulae, Eqs. (1) and (3), are crucial links in the RO retrieval chain. Equation (1) indicates that the inversion of bending angles leads to downward propagation of high altitude errors. Due to the localised kernel $\left(a^{, 2}-a^{2}\right)^{-1 / 2}$ of the inverse Abel transform, this vertical correlation is limited in $N(z)$ but further and stronger error propagation occurs in the hydrostatic integration, Eq. (3). A detailed theoretical analysis of this error propagation has been performed by Rieder and Kirchengast (2001). It is thus vital to use adequate bending angles also at altitudes above any height of interest. On the other hand, since atmospheric density decreases exponentially with height and residuals from the ionospheric correction significantly disturb the RO signal above about $45 \mathrm{~km}$, the high-altitude signal-to-noise ratio (SNR) is low. Without careful initialisation of the two integrals, errors in temperature profiles may propagate down to $20 \mathrm{~km}$ or even below (Gobiet and Kirchengast, 2004), which are altitudes generally considered to be "optimal" for RO retrieval performance.

To cope with this problem, usually both integrals in Eqs. (1) and (3) are initialised by some kind of a priori information about the atmosphere at high altitudes. The standard approach, inherited from planetary occultation (e.g., Fjeldbo et al., 1971), is to independently initialise both integrals. The Abel transform is often initialised by extrapolating the bending angle profile exponentially (e.g., Kursinski et al., 1997). Since the resulting refractivity profile usually lacks quality at high altitudes, the hydrostatic integral is again initialised at some fixed altitude between 30 and $50 \mathrm{~km}$ with temperature (or pressure) upper boundary "guess" value (e.g., Kursinski et al, 1997; Hajj et al., 2004; Wickert et al., 2004), usually derived from a meteorological analysis. A modification of the extrapolation approach is statistical optimisation (Sokolovskiy and Hunt, 1996), which optimally (in a leastsquares error sense) combines the retrieved bending angle profile with a background profile from a climatology or a meteorological analysis, taking into account the error characteristics of both profiles (see Gobiet and Kirchengast (2004) for details). Usually, the hydrostatic integral is subsequently still initialised as described above.

Steiner and Kirchengast (2005) have, in the context of an error analysis based on ensembles of GNSS RO profiles from end-to-end simulations, discussed the weakness of the double initialisation approach and found: "Regarding the climatological use of geopotential heights and temperature this approach is problematic, since it leads to intricate error characteristics and a priori dependence in the stratospheric data down to about $20 \mathrm{~km}$, which threats the crucial aims of unbiasedness and a clear understanding of the degree of residual biasedness." Gobiet and Kirchengast (2004) presented a retrieval scheme avoiding the 2nd initialisation by using full downward integration of the hydrostatic integral from $120 \mathrm{~km}$ in order to eliminate these problems and the related 
Table 1. Overview of the CHAMPCLIM retrieval (CCR) scheme, dry air.

\author{
Early outlier rejection \\ Phase delay smoothing \\ Bending angle retrieval \\ Ionospheric correction
}

Statistical optimisation of bending angles

Abel transform

Hydrostatic integral initialisation Lower cut-off altitude

External quality control (for outlier profiles)

Reference frame, vertical coordinate
" $3 \sigma$ " outlier rejection on $50 \mathrm{~Hz}$ sampling rate L1 and L2 phase delay data, based on a one-second moving window over the profile.

Smoothing of $50 \mathrm{~Hz}$ phase delay profiles using regularization (third order norm, regularization parameter $=10^{5}$, following Syndergaard, 1999).

Geometric optics retrieval (e.g., Kursinski et al., 1997) at both L1 and L2 frequencies.

Linear combination of L1 and L2 bending angles (Vorob'ev and Krasil'nikova, 1994). Correction is applied to low-pass filtered bending angles (1 km moving average), L1 high-pass contribution is added after correction (Hocke et al., 2003). L2 bending angles $<15 \mathrm{~km}$ derived via L1-L2 extrapolation.

Statistical optimisation of bending angles between 30 and $120 \mathrm{~km}$. Vertically correlated background (corr. length $=6 \mathrm{~km}$ ) and observation (corr. length $=1 \mathrm{~km}$ ) errors. Observation error estimated from observed variance of observed profile $>65 \mathrm{~km}$. Background error: $15 \%$. Background information: collocated profile derived from ECMWF operational analysis (T42L60; resp. T42L91 as of 01/02/2006). Above $\sim 60 \mathrm{~km}$ : MSISE-90 (Hedin, 1991). Optional: MSISE-90 climatology as background profiles search library (following Gobiet and Kirchengast, 2004).

Numerical integration over bending angle (Simpson's trapezoidal rule) from each height (impact parameter) to $120 \mathrm{~km}$. Impact parameter to height conversion with radius of curvature at mean tangent point location following Syndergaard (1998).

No initialisation below $120 \mathrm{~km}$. At $120 \mathrm{~km}$ : pressure = pressure (MSISE-90).

The lowermost altitude, where retrieved data is kept, is set to the altitude, where severe impact parameter ambiguities occur (impact parameter increase $>0.2 \mathrm{~km}$ from one data point to the next downwards).

Refractivity $5 \mathrm{~km}-35 \mathrm{~km}: \Delta \mathrm{N} / \mathrm{N}<10 \%$; Temperature $8 \mathrm{~km}-25 \mathrm{~km}: \Delta \mathrm{T}<20 \mathrm{~K}$. Reference: collocated ECMWF operational analysis profiles (T42L60 resp. T42L91 as of 01/02/2006).

Earth figure: WGS-84 ellipsoid; Vertical coordinate: mean-sea-level (MSL) altitude; conversion of ellipsoidal height to MSL altitude (at mean tangent point location) via EGM-96 geoid smoothed to $2^{\circ} \times 2^{\circ}$ resolution. over-accentuation of a priori information in the retrieval.

Following these findings we use in the CCR scheme a statistical optimisation approach that introduces background information exclusively to the bending angles, yielding highquality refractivity profiles up to high altitudes so that effectively no "2nd initialisation" is needed to initialise the hydrostatic integral subsequently. This follows from the fact that the initialisation of the hydrostatic integral with zero pressure at $120 \mathrm{~km}$, compared to initialisation with pressure from the MSISE-90 climatology, has no noticeable effect on the retrieved temperature profiles at any height of interest below the stratopause. $120 \mathrm{~km}$ can be regarded as being outside of the atmosphere from a RO retrieval point of view and effectively no further a priori information needs to be introduced to the retrieval after statistical optimisation of the bending angles. This strategy ingests less a priori information compared to most other RO retrieval schemes and allows clear tracing of the amount of non-observed information entering the retrieval (see Sect. 2.3). As will be shown below based on real data, rather than on simulated data as used by Gobiet and Kirchengast (2004), a significantly higher degree of independence from a priori information can be achieved in the critical 30 to $40 \mathrm{~km}$ altitude range compared to retrieval schemes applying "2nd initialisation" of the hydrostatic integral. A more detailed description of the general methodology can be found in Gobiet and Kirchengast (2004), its specific application to CHAMP data is described as part of the following subsection.

\subsection{The CHAMPCLIM retrieval}

The CHAMPCLIM retrieval (CCR) scheme, more precisely the dry air retrieval core scheme of interest here, starts with phase delays from CHAMP provided by GFZ ("level 2 data") and returns (dry air) profiles of refractivity, density, pressure, geopotential height, and temperature, respectively. Compared to the pre-operational retrieval scheme described in Gobiet and Kirchengast (2004) several aspects were improved for its operational application to CHAMP data and to improve the retrieval performance. Table 1 provides an overview on the main ingredients of the scheme and we briefly describe the main (improvement) aspects below; some more details are described in Gobiet (2005).

More stable ionospheric correction could be achieved by low-pass filtering the signals before dual-frequency correction and adding the high-pass fraction of the stronger signal afterwards (Hajj et al., 2002; Hocke et al., 2003). Tests identified a $1 \mathrm{~km}$-width boxcar filter applied to bending angles and impact parameters being most effective, whilst broader filters created biases above $30 \mathrm{~km}$ and more narrow filters 
were less effective in terms of retrieval efficiency (i.e., a smaller number of occultation events could be successfully processed). Additionally, the retrieval quality in terms of statistical error could be slightly improved in the 15 to $20 \mathrm{~km}$ altitude range.

The statistical optimisation of bending angles needs an estimation of the error characteristics of the data. Unlike several retrieval schemes that use the root-mean-square (RMS) differences relative to the a priori for this purpose we derive observation errors independently from the background by analysing the altitudinal variance of the ionosphere-corrected bending angle profiles at high altitudes, where it predominantly contains noise and the neutral atmospheric contribution to the signal is close to negligible. Compared to the RMS method, this generally reduces the observation error estimate by 10 to $20 \%$ (which does not necessarily mean that the lower value is more realistic). More important are single cases with severely biased background information. Depending on the quality of the background information, such cases can lead to a more than $50 \%$ overestimation of the observation error.

The error estimation was derived from the height interval between 65 and $80 \mathrm{~km}$. Though a lower boundary of $70 \mathrm{~km}$ would better fulfil the low-atmospheric-signal assumption, $65 \mathrm{~km}$ was used in case of CHAMP as compromise for the sake of higher retrieval efficiency. Typically, the observation error standard deviation is estimated to amount to 1 to $4 \mu \mathrm{rad}$ at this altitude. For more recent RO receivers with nominally higher SNR like the GNSS Receiver for Atmospheric Sounding (GRAS) on MetOp (GRAS-SAG, 1998; Loiselet et al., 2000) or the Integrated GPS Occultation Receivers (IGOR) on the COSMIC constellation (Rocken et al., 2000; Wu et al., 2005), it might be meaningful to raise the lower boundary.

As background information we used what we consider to be the best dataset available, the operational analyses of the European Centre for Medium-Range Weather Forecasts (ECMWF, cf. Sect. 3.3.3). Due to ECMWF having started RO data assimilation as of mid December 2006, CCR is scheduled to use short-range forecasts instead of analyses as a priori information beyond 2006 in order to have available sufficiently independent, yet physical consistent a priori profiles with good error characteristics (any potential influence of this change on climatology fields will be checked). For each observed bending angle profile, one collocated set of atmospheric parameters was extracted from the temporally closest of the six-hourly ECMWF analysis fields. This was converted into a refractivity profile (Eq. 2), expanded upwards from $\sim 60 \mathrm{~km}$ (the second-highest level of the ECMWF model) to $120 \mathrm{~km}$ using refractivity derived from the MSISE-90 climatology (Hedin, 1991) and halfGaussian weighting (vertical scale length $7.5 \mathrm{~km}$ ) to ensure a smooth transition, and transformed into a bending angle profile using the forward Abel transform (the inverse of Eq. 1; e.g. Rieder and Kirchengast, 2001; their Eq. 14). The error of the background profile was assumed to amount to $15 \%$ of the background bending angle value at each altitude, which is in reasonable agreement with the climatological variability in the upper stratosphere and lower mesosphere and ensures that the background profile dominates only at the uppermost part of the profile, where the SNR of the observation is small (cf. also Healy, 2001; Rieder and Kirchengast, 2001). Since the bending angle in the atmosphere increases exponentially with decreasing height, the a priori error estimate grows very fast with decreasing height and is not very sensitive to the actual percentage value (values of 5 to $20 \%$ are commonly used and yield comparable results).

Statistical optimisation restricted to altitudes above $30 \mathrm{~km}$ was performed using the inverse covariance weighting approach (Healy, 2001; Rieder and Kirchengast, 2001), which combines the observed and background profile in a statistically optimal way regarding their error characteristics, including vertical error correlation.

To trace errors from bending angle to temperature level in CCR, transformation matrices for background (B), observation $(\mathbf{O})$, and retrieval $(\mathbf{R})$ error covariance matrices $\left(\mathbf{R}=\left(\mathbf{B}^{-1}+\mathbf{O}^{-1}\right)^{-1}\right)$ have been implemented following Syndergaard (1999). As a measure of the relative importance of the background and observed information after the statistical optimisation, profiles of the square root of the ratio of the diagonal elements of the retrieval error and background error covariance matrices were analysed $\left(\mathbf{q}_{r}\right)$, where the retrievalto-background error ratio $\mathbf{q}_{r}$ can be regarded to indicate the fraction of the retrieval error stemming from the background error following Rieder and Kirchengast (2001) (their Eq. 8). $\mathbf{q}_{r}$ allows to define background dominated $\left(\mathbf{q}_{r}>0.5\right)$ and observation dominated $\left(\mathbf{q}_{r}<0.5\right)$ altitude ranges, with the transition height $(h q 50)$ between these two regimes at the altitude where $\mathbf{q}_{r}$ equals 0.5 .

In CCR temperature profiles, $h q 50$ typically lies between 40 and $55 \mathrm{~km}$ and it lies about $4 \mathrm{~km}$ higher for the corresponding bending angle profiles, the actual height primarily depending on the observation error estimate for each given CHAMP bending angle profile. Two exemplary profiles, one with $h q 50=40 \mathrm{~km}$ ("low" case) and one with $h q 50=57 \mathrm{~km}$ ("high" case) are displayed in Fig. 1. These two cases mark the range of virtually all CCR temperature profiles for which error estimation as described above could be performed. However, about one quarter of all CHAMP phase delay profiles showed data weaknesses at high altitudes where the observation error is estimated (indicated by negative bending angles in ionosphere-corrected bending angle profiles above some height). In these cases we down-weighted the observation by assuming a large observation error $(50 \mu \mathrm{rad})$ which results in lowering $h q 50$ to about $32 \mathrm{~km}$. We regard a more sophisticated treatment of these profiles, part of on-going work on CCR upgrades, as a major possibility for further reducing the dependence of CCR from background information.

After application of the inverse Abel transform, a high quality refractivity profile is available, which can be directly processed via the hydrostatic integral without adding further 


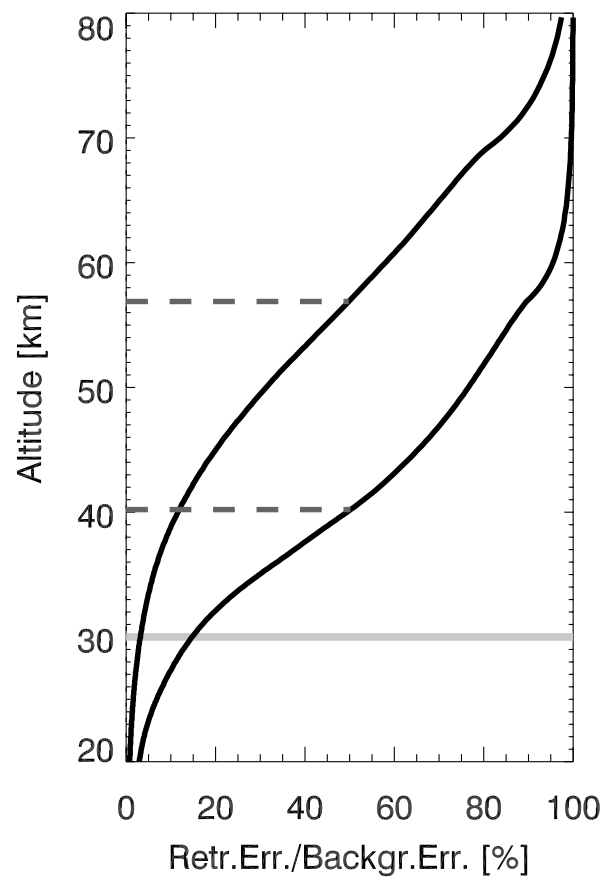

Fig. 1. Retrieval-to-background temperature error ratio profiles (in percent, $100 \cdot \mathbf{q}_{r}$ ) for two cases corresponding to approximately the upper and lower limits of $\mathbf{q}_{r}$ in CCR (more details and exception see text). hq50 is indicated by dark-grey dashed lines, the $30 \mathrm{~km}$ level by a light-grey solid line.

background information. For the sake of correctness, the integral is initialised with pressure derived from MSISE-90 at $120 \mathrm{~km}$, but simply starting the integration from zero produces negligible differences in the results in the domain of interest below $50 \mathrm{~km}$. Note that this does not imply that the observations significantly contribute to the retrieved temperature above about $65 \mathrm{~km}$. The "effective" initialisation height, where retrieved temperature essentially equals the temperature corresponding to the background bending angle profile $\left(\mathbf{q}_{r}>0.95\right)$, lies within about 60 to $77 \mathrm{~km}$ (see Fig. 1).

Finally, a rough quality control is applied in order to remove outlier profiles featuring a relative refractivity difference greater than $10 \%$ between 5 and $35 \mathrm{~km}$ or a temperature difference greater than $20 \mathrm{~K}$ between 8 and $25 \mathrm{~km}$, respectively, compared to the collocated ECMWF profile. The acceptance ranges have been deliberately chosen that large (more than an order of magnitude larger than the standard errors of any of the two datasets) to ensure that indeed only severe outliers, caused by technically corrupted data, are rejected and that eventual biases in the reference dataset (ECMWF) are not introduced into the statistics of the RO retrieval results. The entire CCR quality control system (including the rejection of technical corrupted data during the retrieval) removes about $10 \%$ of the profiles entering the retrieval (GFZ level 2 data at phase delay level).

\section{Validation methodology and correlative data}

A range of suitable correlative datasets were used to validate the CCR scheme temperature product in order to derive a well-founded estimation of the retrieval performance characteristics. Though the correlative data in general feature error characteristics larger than can be expected from the RO method, the combination of these comparisons provides a well-balanced picture of the retrieval performance, particularly on upper bounds of eventual biases.

\subsection{Validation periods and spatial setup}

Out of 20 available seasons analysed (September 2001 to August 2006; cf., e.g., Borsche et al., 2007), two representative seasons were selected to be closely validated and presented in more detail here: September, October, and November 2002 (SON 2002) and June, July, and August 2003 (JJA 2003). Figure 2 illustrates the coverage. SON 2002 is, regarding the comparison of CCR RO to correlative data, a representative typical season and JJA 2003 stands for a more "extreme" season featuring prominent deviations between the datasets. A further practical reason for selecting these periods was the limited availability to us of the Envisat correlative datasets (see Sect. 3.3.2) in other seasons.

In order to be able to analyse not only seasonal, but also latitudinal effects, the two seasonal samples were further separated into latitudinal sub-samples: low latitudes $\left(-30^{\circ}\right.$ to $\left.+30^{\circ}\right)$, mid latitudes $\left( \pm 30^{\circ}\right.$ to $\left.\pm 60^{\circ}\right)$, and high latitudes ( $\pm 60^{\circ}$ to $\pm 90^{\circ}$ ) for the depiction of error statistics profiles, and 18 ten-degree latitude samples (bounded by black lines in Fig. 2) for the depiction of zonal-mean latitude versus altitude plots of the bias (Sect. 4). The latitudinal separation is particularly important since the quality of both the CCR and the correlative data may depend on latitude. Additionally, bias estimates including significance level indication are summarised in a more compact manner (Sect. 5) by averaging over $10 \mathrm{~km}$ altitude intervals (10 to $20 \mathrm{~km}, 20$ to $30 \mathrm{~km}$, 30 to $40 \mathrm{~km}$ ). The uppermost interval is of particular interest for judging the influence of a priori information on the retrieval and the lower and middle intervals mark the best performance $\mathrm{RO}$ retrieval range.

The spatial coverage of CHAMP occultation events is denser near the poles than at low latitudes due to the high inclination $\left(87^{\circ}\right)$ of the CHAMP orbit. This affects particularly the density of coincidences with profiles from a dataset with qualitatively similar coverage characteristics such as MIPAS, as clearly visible in Fig. 2.

\subsection{Validation methodology}

The validation methodology is based on simple statistics of differences between CCR RO dry temperature profiles and temperature profiles from the other data sources. Since no data below $10 \mathrm{~km}$ are compared, the water-vapour effect in 

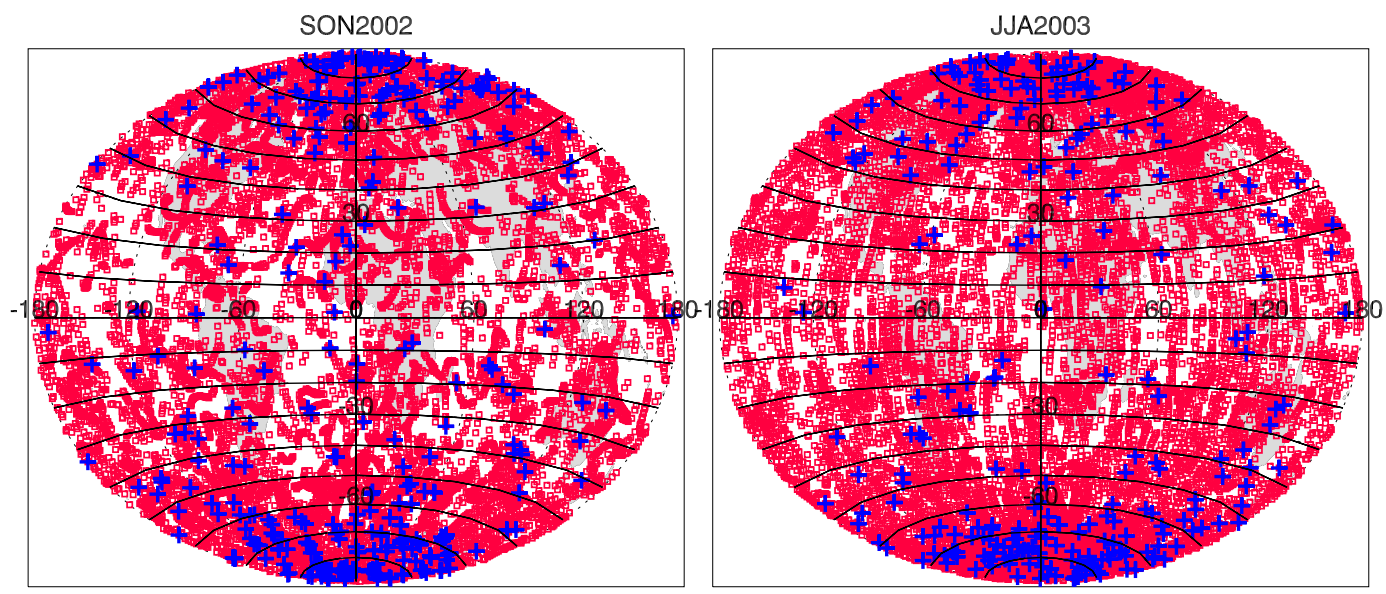

Fig. 2. Geographical distribution of CHAMP events (red squares) and coinciding MIPAS profiles (blue crosses) in SON 2002 (12950 CHAMP profiles, 368 coincidences, left panel) and JJA 2003 (13655 CHAMP profiles, 254 coincidences, right panel). The black circles of latitudes indicate the latitudinal separation into 18 ten-degree bands of zonal-mean sub-ensembles.

dry temperature can be neglected for our purposes (e.g., Gobiet, 2005) and dry temperatures can be regarded as actual temperatures (small potential differences remaining in the tropical latitudes up to about $12 \mathrm{~km}$ are easily diagnosed). For each CCR profile, a collocated correlative profile is searched (the definition of collocation is given in the following subsections) and, if found, vertically linearly interpolated to the CCR standard altitude levels (regular $200 \mathrm{~m}$ level spacing). The correlative profile is then subtracted from the CCR profile and the difference profile $\Delta \mathbf{x}$ is added to the validation ensemble from which error statistics are derived. The ensemble mean profile represents the systematic difference (bias profile $\mathbf{b}$ ) and the subtraction of $\mathbf{b}$ from each difference profile gives a centred (unbiased) ensemble of difference profiles from which the ensemble variance profile (mean squared centred difference at each altitude level) and its square root, the standard deviation profile $\mathbf{s}$, are estimated. While $\mathbf{s}$ characterises the statistical variability of the differences, the uncertainty of the bias $\mathbf{b}$ is characterised at any given altitude level by the standard deviation profile of the mean, $\mathbf{s} / N^{1 / 2}$, $N$ being the ensemble size. All comparisons in this study are based on $\mathbf{b}$ and $\mathbf{s}$, separating the systematic (b) from the random (s) part of the more frequently used aggregate root-mean-square error. Furthermore, $2 \times \mathbf{s} / N^{1 / 2}$ is used as a $2 \sigma$-measure of statistical significance ( $95 \%$ level) of the estimated biases (Sect. 5).

Since we are not only interested in quantifying the discrepancies between different observational and modelled data but also in their relation to the actual state of the atmosphere, including effects of inadequate vertical resolution, we did deliberately not match the resolutions, e.g., by adjusting the averaging kernels as described by Rodgers and Connor (2003). Resolution-induced differences were found to point to interesting atmospheric structures so we considered it counterproductive to smooth them out in the context of this study.
Regions featuring differences primarily due to lacking resolution of correlative data are readily diagnosed by comparing the full-resolution bias profiles with $10 \mathrm{~km}$ mean biases.

We note that the validation and error analysis presented here is not intended to quantify the climatological error of gridded RO climatologic datasets derived from CHAMP (see Foelsche et al., $2007^{2}$, for this purpose), which would additionally include sampling errors caused by the non-uniform and limited spatial and temporal measurement profile distribution and resolution effects. Here, we rather restrict the analysis to combined observational error of collocated temperature profiles, i.e., we minimise sampling errors. This allows direct insight into the RO retrieval accuracy, together with the accuracy of the correlative datasets, and, based on the diversity and various known strength and weaknesses of the different datasets allows isolation of valuable information on the individual dataset quality.

\subsection{Correlative datasets}

\subsubsection{Operational GFZ retrieval}

Temperature profiles from the most recent operational CHAMP-GFZ retrieval (version 5; e.g., Wickert et al., 2004) are used for a focused analysis of the effects of different elements in RO retrieval strategies. This yields no comprehensive information on the overall RO retrieval performance but rather estimates structural retrieval uncertainty starting from phase delays. Von Engeln (2006) performed a similar study for the entire RO retrieval process by comparing CHAMP data from two independent processing centres. The GFZ retrieval employs statistical optimisation of bending angle

\footnotetext{
${ }^{2}$ Foelsche, U., Borsche, M., Steiner, A. K., Gobiet, A., Pirscher, B., Kirchengast, G., Wickert, J., and Schmidt, T.: Observing Upper Troposphere-Lower Stratosphere Climate with Radio Occultation Data from the CHAMP Satellite, Clim. Dynamics, submitted, 2007.
} 
profiles using the MSISE-90 climatology (Hedin et al., 1991) as a priori data and adds further a priori information derived from operational ECMWF analyses by initialising the hydrostatic integral at $43 \mathrm{~km}$ (i.e., the systematic and random error of ECMWF at $43 \mathrm{~km}$ is assumed to be zero). This results, similar to other double-initialisation schemes described in literature (e.g., Hajj et al., 2004), in overemphasis of ECMWF a priori information and physically inconsistent refractivity and temperature profiles near the "2nd initialisation" upper boundary. We note that an enhanced version of the GFZ retrieval is scheduled to be released later in 2007 (J. Wickert, personal communication, 2007). Evaluation studies showed that RO temperatures in general and CHAMP-GFZ temperatures in particular are derived with a statistical error of less than $1 \mathrm{~K}$ between 10 and $30 \mathrm{~km}$ (Hajj et al., 2002; Wickert et al., 2004) though it has also been shown that GFZ temperatures above $25 \mathrm{~km}$ are cold biased by $1-2 \mathrm{~K}$ (Wang et al., 2004; Wickert et al., 2004).

The vertical resolution of GFZ profiles can be regarded to be similar to CCR profiles $(\sim 1 \mathrm{~km})$, neglecting minor differences in the retrieval process. Collocation of CCR and GFZ profiles is trivially achieved by selecting the same CHAMP measurement. Since CCR uses quality controlled phase delay data from GFZ (i.e., only data that could be processed with the operational GFZ retrieval as well), the entire set of CCR temperature profiles could be used and a total of 26605 difference profiles entered the error statistics, 12950 in SON 2002 and 13655 in JJA 2003, 10926 at high latitudes, 9299 at mid-latitudes, and 6344 at low latitudes.

\subsubsection{Envisat instruments MIPAS and GOMOS}

Comparison to other remote sensing instruments is of particular importance in order to independently evaluate CCR results. We present comparisons with two instruments onboard ESA's (European Space Agency) Envisat satellite, the Michelson Interferometer for Passive Atmospheric Sounding (MIPAS) (Fischer and Oelhaf, 1996; European Space Agency, 2000) and the Global Ozone Monitoring by Occultation of Stars (GOMOS) (Bertaux et al., 1991; Kyrölä et al., 2004) instrument.

MIPAS is a Fourier transform spectrometer for the measurement of gaseous mid-infrared emission spectra at the Earth's limb. It is dedicated to distribute profiles of atmospheric constituents from $6 \mathrm{~km}$ to $70 \mathrm{~km}$ altitude with a vertical resolution of about $3 \mathrm{~km}$ between 6 and $42 \mathrm{~km}$ and a horizontal resolution between $300 \mathrm{~km}$ and $500 \mathrm{~km}$ along track. Since thermal emissions in the infrared are sensitive to temperature, MIPAS is also capable to measure temperature. The temperature profiles used for this study were retrieved by the Institut für Meteorologie und Klimaforschung (IMK) in Karlsruhe (version V3O_T_8). Though ECMWF analyses are used as a priori in the retrieval process, MIPAS is not biased against ECMWF, since the latter data are used within a smoothness constraint matrix of the type $\gamma L_{1}^{T} L_{1}$, where $\gamma$ is a scaling factor and $L_{1}$ is a first order finite differences operator. The use of the first order finite differences operator does not constrain the column information but only how this information is distributed over altitude (von Clarmann and Grabowski, 2007). For the focus of this study, inspection of biases, MIPAS can be regarded as independent from CCR and ECMWF for biases in those data being vertically resolvable by MIPAS. More details about the MIPAS temperature retrieval are described in von Clarmann et al. (2003a, b).

For individual profiles, MIPAS temperatures have been reported to be retrieved with a total error of 0.5 to $1.5 \mathrm{~K}$ (von Clarmann et al., 2003a) and comparisons to other instruments confirmed these figures in principle (with few exceptions) (Wang et al., 2004, 2005). It has also been demonstrated that the difference in vertical resolution to RO measurements significantly influences the comparison with RO profiles only in the tropopause region (Wang et al., 2004).

Due to MIPAS' sensitivity to clouds, the number of available measurements per day varies from several tens to hundreds. When this study was performed, 68 days of MIPAS data from the most recent retrieval version were available in the two evaluation periods (SON 2002: 04/09/2002, 05/09/2002, 12-14/09/2002, 1 28/092002, 17/10/2002, 25/10/2002, 26/10/2002, 4/11/2002, $5 / 11 / 2002, \quad 7-9 / 11 / 2002, \quad 11-13 / 11 / 2002, \quad 15 / 11 / 2002$, 22/11/2002, 23/11/2002, 29/11/2002, 30/11/2002; JJA 2003: $05-09 / 06 / 2003,12 / 06 / 2003,13 / 06 / 2003,24 / 06 / 2003$, 25/06/2003, 29/06/2003, 30/06/2003, 01/07/2003, $05 / 07 / 2003, \quad 06 / 07 / 2003,14 / 07 / 2003,16-18 / 07 / 2003$, 26-31/07/2003, 05/08/2003, 06/08/2003, 16-18/08/2003, $26-28 / 08 / 2003$, 30/08/2003, 31/08/2003), all together yielding 24187 profiles. As collocation criteria a maximum horizontal distance of $300 \mathrm{~km}$ and a maximum time difference of $3 \mathrm{~h}$ were allowed. 622 CHAMP profiles met these criteria, most of them at high latitudes (441), but still a statistically reasonable number at mid (122) and low (59) latitudes (cf. Fig. 2). In cases where more than one MIPAS profile met the collocation criteria, the average of the collocated profiles was used for comparison with CCR RO.

GOMOS, a further Envisat instrument for atmospheric sounding, exploits stellar occultation (i.e., the information carried by a star's light when it is modified during its travel through the Earth's atmosphere as the star sets behind the horizon) with the major objective of monitoring ozone and ozone depleting trace gases in the altitude range between $15 \mathrm{~km}$ and $90 \mathrm{~km}$. In addition, GOMOS data can be addressed to retrieve bending angle, density, pressure, and temperature profiles. Results from a temperature retrieval based on bending angle profiles extracted from GOMOS star tracker data are used for comparison with CCR RO. The retrieval chain roughly follows the CCR scheme explained in Sect. 2.3. Details are discussed in Retscher et al. (2004, 2006). The vertical resolution of GOMOS temperature profiles is about $1.7 \mathrm{~km}$ corresponding to a sampling rate of $2 \mathrm{~Hz}$. 
Only a very limited amount of GOMOS data was available for this study, resulting in 49 collocated temperature profiles (same collocation criteria as for MIPAS), most of them at high latitudes. In order to retain reliable statistics, no further separation into latitudinal sub-ensembles was performed.

\subsubsection{NWP analyses}

Analyses of numerical weather prediction (NWP) centres combine short-range model forecasts with various sources of observational data. In the stratosphere they are predominantly constrained by radiosondes (up to $25-30 \mathrm{~km}$ ) as well as low vertical resolution satellite-derived radiances like those of the Advanced Microwave Sounding Unit A (AMSUA). Their reliability is best in the troposphere and lower stratosphere and decreases in the middle and upper stratosphere due to decreasing availability and quality of observations, particularly over polar regions and the oceans. We collected data from five major analysis systems for comparison with CCR RO temperature profiles.

The first ones, ECMWF operational analyses are also used in CCR as a priori information above $30 \mathrm{~km}$ (cf. Sect. 2.3) and can therefore not be regarded as an entirely independent evaluation dataset. Their importance here as correlative dataset is for assessment of the level of (in)dependence of CCR RO temperatures from its ECMWF constraint at high altitudes (above $25 \mathrm{~km}$ ) and for use as independent evaluation dataset below about $25 \mathrm{~km}$. The analysis version operational during our evaluation periods used 60 vertical levels up to $0.1 \mathrm{hPa}$, spectral representation in the horizontal with triangular truncation at wave number 511 (T511, corresponds to $\sim 40 \mathrm{~km}$ grid spacing) for upper air fields and horizontal derivatives, and a Gaussian grid in the horizontal for dynamic tendencies and diabatic physical parameterisations (ECMWF, 2004). The operational forecasts are started twice a day from the initial state (i.e., the previous analysis), produced via four-dimensional data assimilation. Analyses are produced for 00:00, 06:00, 12:00, and 18:00 UTC every day.

For this comparison, ECMWF analyses have been extracted from the ECMWF data archive on model levels at full vertical resolution $(>1.5 \mathrm{~km}$ in the tropopause region, i.e., somewhat coarser than CCR RO) and reduced horizontal resolution (T42, corresponds to $\sim 300 \mathrm{~km}$, which is roughly the horizontal resolution of RO measurements). Vertical profiles of temperature bi-linearly interpolated to the mean tangent point of the occultation event were derived from the nearest analysis time layer, which ensured that the maximum time difference between the CCR and the ECMWF profile corresponds to the collocation criteria for MIPAS and GOMOS, and linearly interpolated to the CCR standard altitude levels. Since ECMWF analyses are available for the entire evaluation periods, the entire set of CCR profiles (26605) could be used for evaluation, as for the comparison to GFZ RO retrievals.
Further analyses used for comparison were provided in the framework of the Stratospheric Processes And their Role in Climate (SPARC) project and are particularly important to estimate the uncertainty of recent analyses in different altitudes and at different latitudes in order to allow a proper interpretation of the comparison results. These analysis data are interpolated linearly in time, bi-linearly in the horizontal to the CHAMP observation locations, and linearly to the CCR standard altitude levels. Descriptions of each of the assimilation/analysis systems are given by Manney et al. (2005a).

GEOS-4 (Goddard Earth Observing System, Version 4.03; Bloom et al., 2005) analyses from NASA's Global Modeling and Assimilation Office are provided on a $1^{\circ} \times 1.25^{\circ}$ latitude $\times$ longitude grid on 55 model levels from the surface to $0.01 \mathrm{hPa}$. The fields are six-hour averages valid at 00:00, 06:00, 12:00, and 18:00 UTC. Analyses from the UK Met Office (referred to as MetO analyses; Swinbank et al., 2002) are provided by the British Atmospheric Data Centre (BADC) once daily at 12:00 UTC. They are on a $2.5^{\circ} \times 3.75^{\circ}$ latitude $\times$ longitude grid, on six levels per decade in pressure ("UARS pressure levels", 40 levels in total) from 1000 to $0.1 \mathrm{hPa}$. NCEP/CPC (National Centers for Environmental Prediction/Climate Prediction Center) analyses are available once daily at 12:00 UTC, provided on a $65 \times 65$ point polar stereographic grid for each hemisphere. The fields used here have been interpolated bi-linearly to a $2.5^{\circ} \times 5^{\circ}$ latitude $\times$ longitude grid prior to the interpolation to the CHAMP locations. They are available on 18 pressure levels from 1000 to $0.4 \mathrm{hPa}$. The NCEP/NCAR (NCEP, National Center for Atmospheric Research) 50 year reanalysis (NCEP Rean) data are daily average fields valid at 12:00 UTC, on a $2.5^{\circ} \times 2.5^{\circ}$ latitude $\times$ longitude grid. There are 17 pressure levels from 1000 to $10 \mathrm{hPa}$. NCEP Rean data are considered unsuitable for detailed stratospheric studies, since the temperatures are severely biased according to Manney et al. (2005a, b).

\section{Results and discussion}

The results of the comparisons are presented as latitude versus altitude slices of zonal-mean bias as well as in form of bias \pm standard deviation profiles separated into global domain and low, mid, and high latitudes, respectively. For GOMOS, due to the limited collocation ensemble, only global mean difference statistics are presented and discussed. For the analyses other than ECMWF, the results are shown and discussed as latitude versus altitude slices only. The displayed altitude range is 10 to $40 \mathrm{~km}$, of which 10 to $30 \mathrm{~km}$ is generally regarded as the reliable (best performance) range for RO measurements, and 30 to $40 \mathrm{~km}$ marks the potentially a priori influenced, but still measurement dominated range. The maximum usable altitude of properly processed standalone RO products can be expected to be found within 30 to $40 \mathrm{~km}$. Soon above $40 \mathrm{~km}$ a RO profile quickly becomes a 


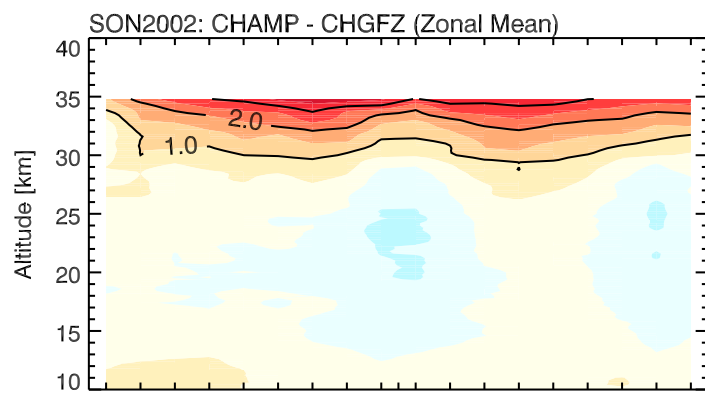

$-85-75-65-55-45-35-25-15-5051525354555657585$ Latitude [deg]
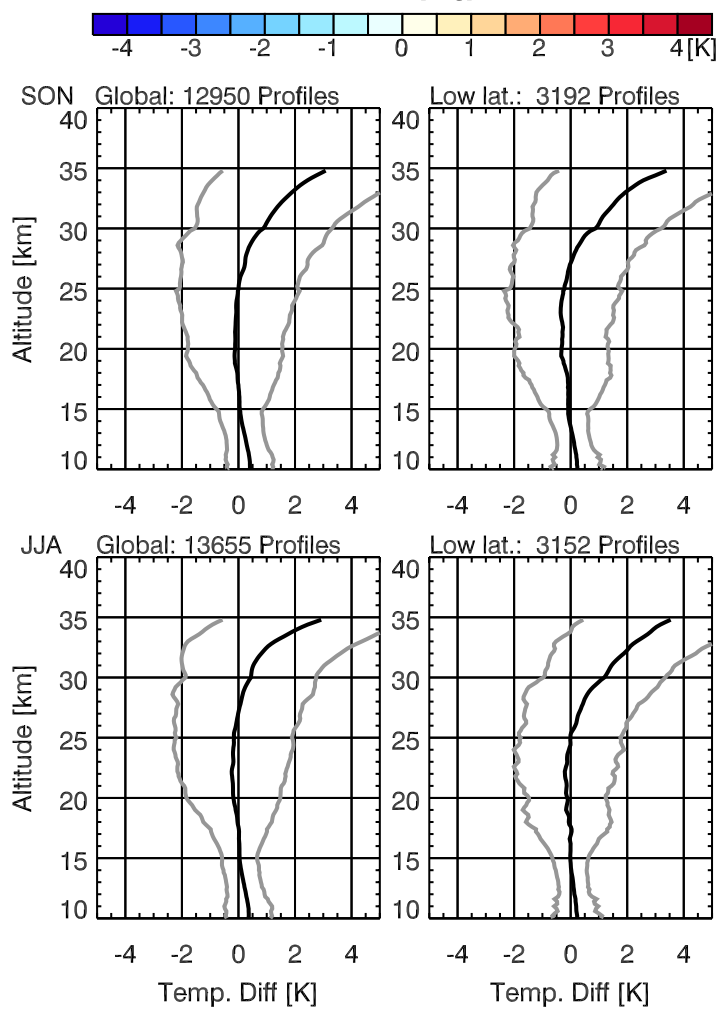

$\begin{array}{lllll}-4 & -2 & 0 & 2 & 4\end{array}$

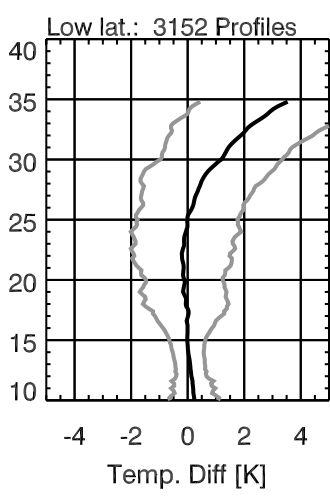

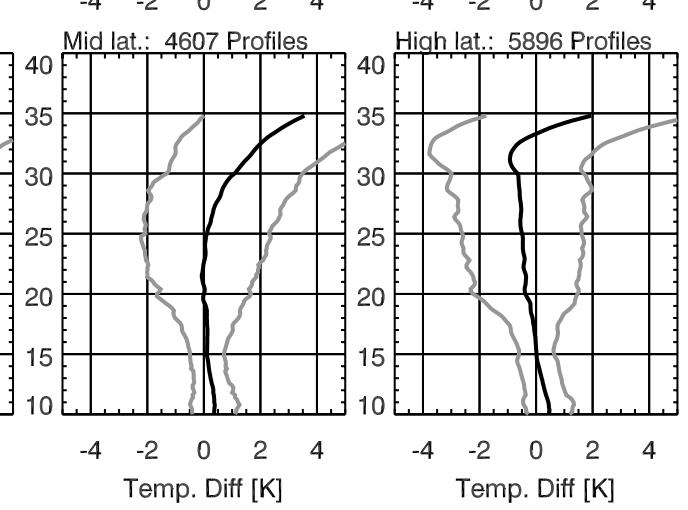

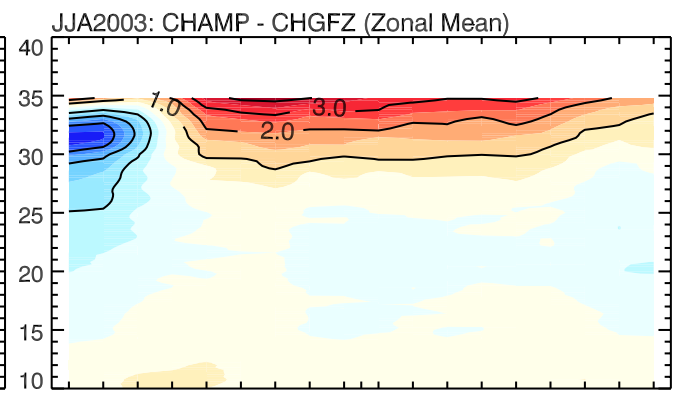

$-85-75-65-55-45-35-25-15-5051525354555657585$ Latitude [deg]
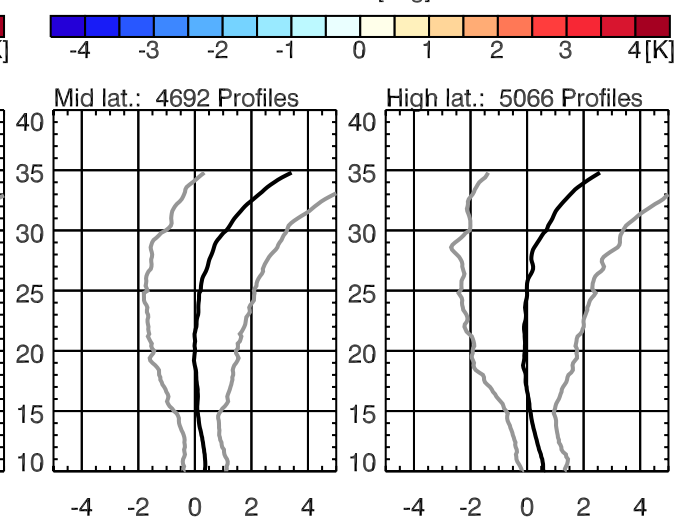

Fig. 3. CCR CHAMP temperature differences relative to operational GFZ CHAMP retrievals, i.e., positive values correspond to higher CCR temperatures. Top row: Systematic differences (bias) in 18 latitude bands (left: SON 2002, right JJA 2003). Middle and bottom row, from left to right: Global, low latitude $\left(-30^{\circ}\right.$ to $\left.30^{\circ}\right)$, mid latitude $\left( \pm 30^{\circ}\right.$ to $\left.\pm 60^{\circ}\right)$, and high latitude $\left( \pm 60^{\circ}\right.$ to $\left.\pm 90^{\circ}\right)$ bias $($ black $) \pm$ standard deviation profiles (grey) for SON 2002 (middle) and JJA 2003 (bottom), respectively.

priori dominated (details depending on the high altitude initialisation strategy used; cf. Gobiet and Kirchengast, 2004, and Sect. 2.3). White areas in the plots correspond to missing correlative data. Statistical significance is not displayed, but generally any bias larger than $\sim 0.2 \mathrm{~K}$ can be regarded as statistically significant on the $2 \sigma$-level ( $\sim 95 \%$ significance). A more condensed view on the results including significance indication follows in Sect. 5.

\subsection{Comparison to operational GFZ CHAMP temperatures}

Figure 3 illustrates the intercomparison results between CCR and GFZ retrievals from CHAMP. Due to the decreasing ac- curacy above $30 \mathrm{~km}$, operational CHAMP temperature profiles from GFZ are delivered for altitudes up to $35 \mathrm{~km}$ only. Generally, as Fig. 3 shows, the differences to CCR temperatures are small below about $26 \mathrm{~km}(<0.5 \mathrm{~K})$ with standard deviations of 1 to $2 \mathrm{~K}$. At higher altitudes CCR is increasingly warmer than GFZ, reaching about $3 \mathrm{~K}$ difference at $35 \mathrm{~km}$. Parts of this bias can be attributed to the treatment of a priori information in the GFZ retrieval (see Sect. 3.3.1). As will be shown in Sect. 4.4 later, the source of this bias is a general cold bias (except southern JJA high latitudes) in ECMWF temperatures above $30 \mathrm{~km}$, to which the GFZ retrieval is more strongly attached than the CCR. Additional 


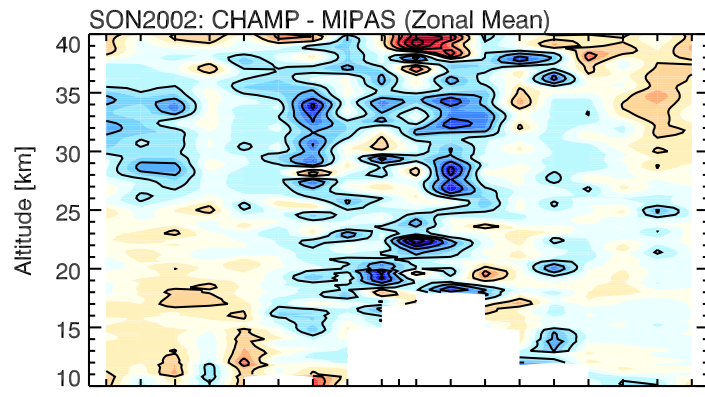

-85-75-65-55-45-35-25-15 -505 1525354555657585 Latitude [deg]
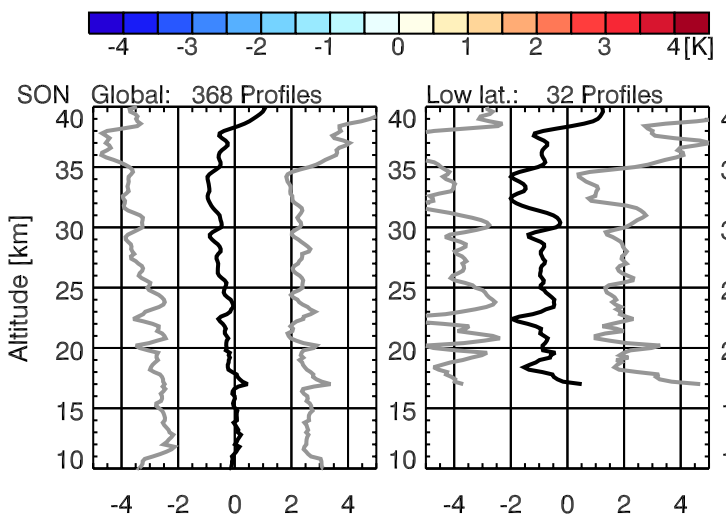

$\begin{array}{lllll}-4 & -2 & 0 & 2 & 4\end{array}$

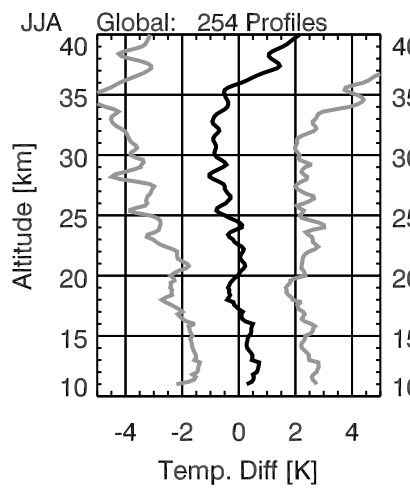

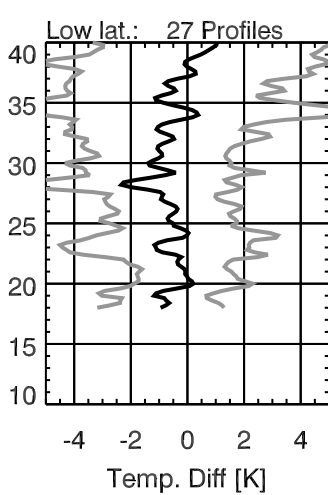

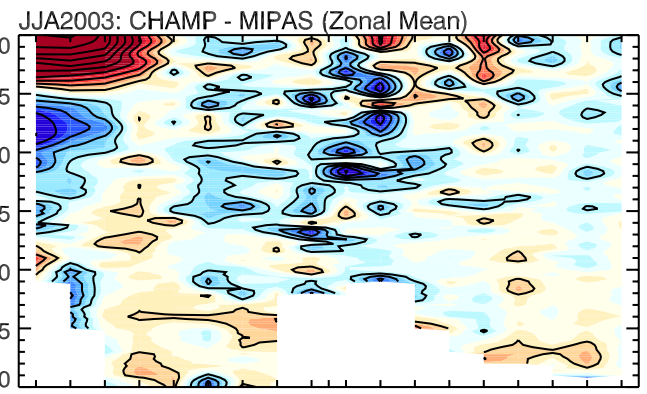

$-85-75-65-55-45-35-25-15-5051525354555657585$ Latitude [deg]

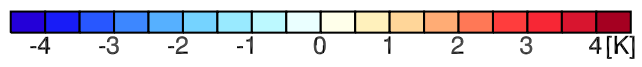

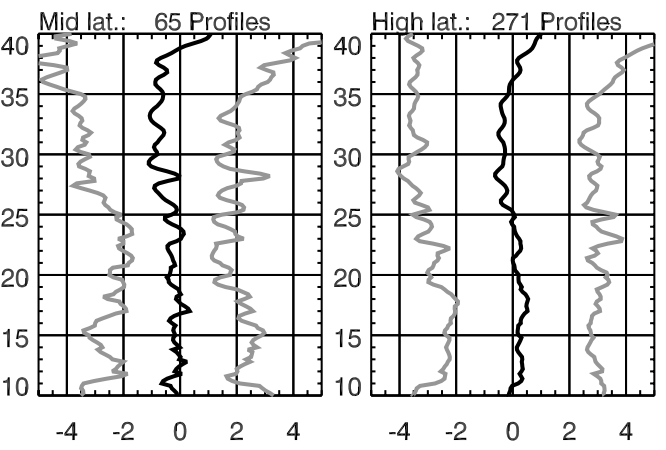

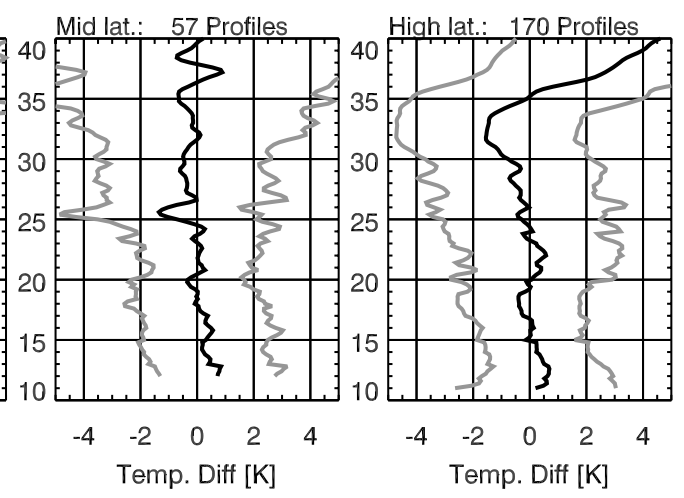

Fig. 4. CCR CHAMP temperature differences relative to Envisat MIPAS retrievals. Same format as Fig. 2.

causes could be a numerical incorrectness found in the GFZ retrieval (J. Wickert, personal communication, 2007) and the influence of the MSIS a priori information used for statistical optimisation in that retrieval. A similar bias of the GFZ operational temperatures has been found by Wang et al. (2004) relative to MIPAS (1 to $1.5 \mathrm{~K}$ at $30 \mathrm{~km}$ ), by Wickert et al. (2004) relative to radiosondes (about $2 \mathrm{~K}$ at $35 \mathrm{~km}$ ), and by von Engeln (2006) relative to UCAR (University Cooperation for Atmospheric Research) RO retrievals (about $2 \mathrm{~K}$ at 31 to $33 \mathrm{~km}$ ). The important conclusion of this comparison is that the way of introducing a priori data into the RO retrieval can significantly influence the retrieved temperature profile result down to about $26 \mathrm{~km}$ even in well tested operational retrieval schemes, in line with studies by, e.g., Steiner et al. (1999), Marquardt et al. (2003), Hajj et al. (2004), and
Steiner and Kirchengast (2005). Additionally, a bias reaching to about $20 \mathrm{~km}$ is visible at southern high latitudes of JJA 2003, which will be discussed in Sect. 4.4.

\subsection{Comparison to Envisat MIPAS temperatures}

Figure 4 illustrates the intercomparison results between CCR CHAMP and MIPAS, which exhibits a different picture than Fig. 3. In the global mean, the bias stays below 0.5 to $1 \mathrm{~K}$ in the entire altitude range up to $40 \mathrm{~km}$, except for a deviation caused by a severe bias in the JJA 2003 southern high latitudes (bottom, right panel; also see Sect. 4.4). In the latitudinal comparison the bias stays at below $2 \mathrm{~K}$ (standard deviation about $2.5 \mathrm{~K}$ ) except for a peak in JJA 2003 at low latitudes near $29 \mathrm{~km}$ (bottom, middle-left panel) which can 


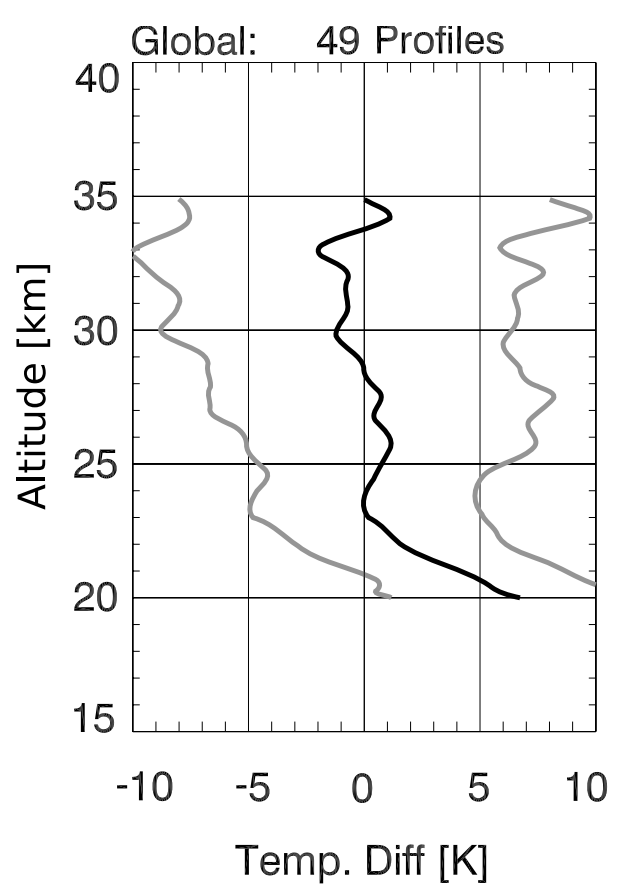

Fig. 5. CCR CHAMP temperature differences relative to Envisat GOMOS retrievals from star tracker data. Bias (black) \pm standard deviation profiles (grey) for an ensemble from SON 2002 (plus one day in December 2002).

be attributed to the lower MIPAS vertical resolution and also the rather small ensemble size of less than 30 profile pairs, and the JJA high latitude bias mentioned before. There is no sign of a general CCR warm bias above $30 \mathrm{~km}$ like in the comparison to GFZ. Since MIPAS can be regarded as virtually independent from ECMWF for biases, this indicates that CCR is as well independent to significant extent from its high-altitude initialisation data (ECMWF) up to $40 \mathrm{~km}$. We find that the only severe deviation that cannot be explained by the different CHAMP and MIPAS vertical resolution is in the JJA 2003 southern high latitudes above $30 \mathrm{~km}$ (Sect. 4.4), which is also present in the comparison to other correlative datasets (see Sect. 4.5). The systematic differences are statistically significant in most regions but fairly small compared to the combined general error characteristics of $\mathrm{RO}(\sim 1 \mathrm{~K})$ and MIPAS ( 0.5 to $1.5 \mathrm{~K}$ ). This is particularly encouraging, since MIPAS and CCR RO are independent from each other.

\subsection{Comparison to Envisat GOMOS temperatures}

Due to the limited GOMOS data availability for this study, only a small ensemble could be used for intercomparison here (49 collocations in total) and no latitudinal separation has thus been done. All profiles analysed are in the period SON 2002 plus one day of December 2002. Figure 5 shows the intercomparison results (the scale of the abscissa is extended compared to other figures). Recall that GOMOS tem- peratures are from star tracker data (Sect. 3.3.2). The comparison shows a severe deviation below $25 \mathrm{~km}$ (up to about $6 \mathrm{~K}$ ), and biases below $2 \mathrm{~K}$ from 25 to $35 \mathrm{~km}$ with a standard deviation of 5 to $8 \mathrm{~K}$. Due to the large standard deviation and the small ensemble only biases larger than about $2 \mathrm{~K}$ can be regarded as statistically significant at the $2 \sigma$-level. Since the GOMOS temperatures are preliminary data on a small dataset (a more advanced temperature product based on GOMOS fast photometer data is currently under development; V. Sofieva, FMI Helsinki, Finland, personal communications, 2006), this comparison mainly demonstrates the value of CCR RO data for evaluation of new remote sensing products. The bias below $25 \mathrm{~km}$ is significant and can be attributed to GOMOS, since CCR comparisons to the other correlative dataset give no indication for such a bias in CCR retrievals. Further results from comparisons of GOMOS data to CHAMP and ECMWF data are discussed by Retscher et al. (2006).

\subsection{Comparison to ECMWF analysis temperatures}

Figure 6 illustrates the intercomparison results between CCR CHAMP and ECMWF temperatures. ECMWF analyses generally agree very well with CCR temperatures (bias $<0.5 \mathrm{~K}$ in most regions below $30 \mathrm{~km}$, accompanied by standard deviations of $\sim 1.5$ to $2.5 \mathrm{~K}$ ) with three remarkable exceptions: An oscillatory bias structure in JJA 2003 at southern high latitudes (polar vortex), a bias in the vicinity of the low latitude tropopause, and a general bias over all latitudes above $30 \mathrm{~km}$.

The oscillatory bias has been shown to be a feature of ECMWF's representation of the polar vortex in the analyses and is probably an artefact from bias adjustments in the ECMWF data assimilation system in data sparse regions (Gobiet et al., 2005). It can be found in any JJA season from 2002 to 2006 to varying extent (not shown). The polar vortex bias seems to be the most severe bias in ECMWF analyses and a combined inspection of Fig. 4 (CCR vs. MIPAS) and Fig. 6 (CCR vs. ECMWF) indicates that this bias (relative to the presumed "true" state of the atmosphere) above $30 \mathrm{~km}$ might be even larger than indicated by the comparison with CCR (about $10 \mathrm{~K}$ or more). Such a large bias in the high-altitude initialisation data degrades the CCR retrievals down to about $30 \mathrm{~km}$ (see Figs. 3, 4, and 7). However, this comparative inspection indicates as well that this downward propagated bias is restricted to the JJA southern high latitudes above $30 \mathrm{~km}$ in CCR RO data.

The tropical tropopause bias is present in any season from 2002 to winter 2005/2006 and has been found as well to be attributable to ECMWF analyses (Gobiet et al., 2005; Borsche et al., 2007). It was probably related to underrepresented atmospheric wave activity in the ECMWF model and is found strongly reduced since an update and resolution improvement of the ECMWF model system, which became operational in February 2006 (Borsche et al., 2007). 


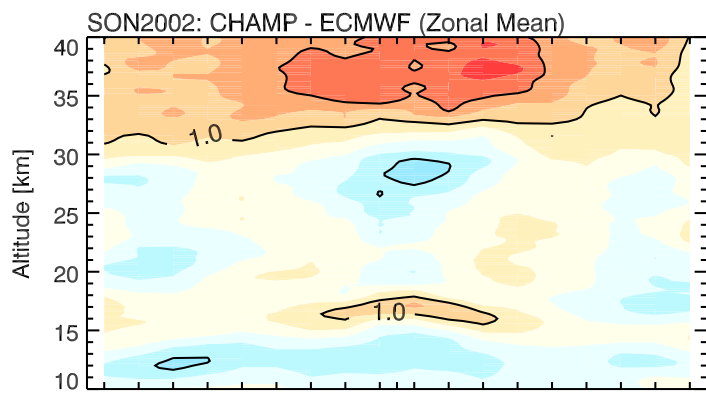

$-85-75-65-55-45-35-25-15-5051525354555657585$ Latitude [deg]
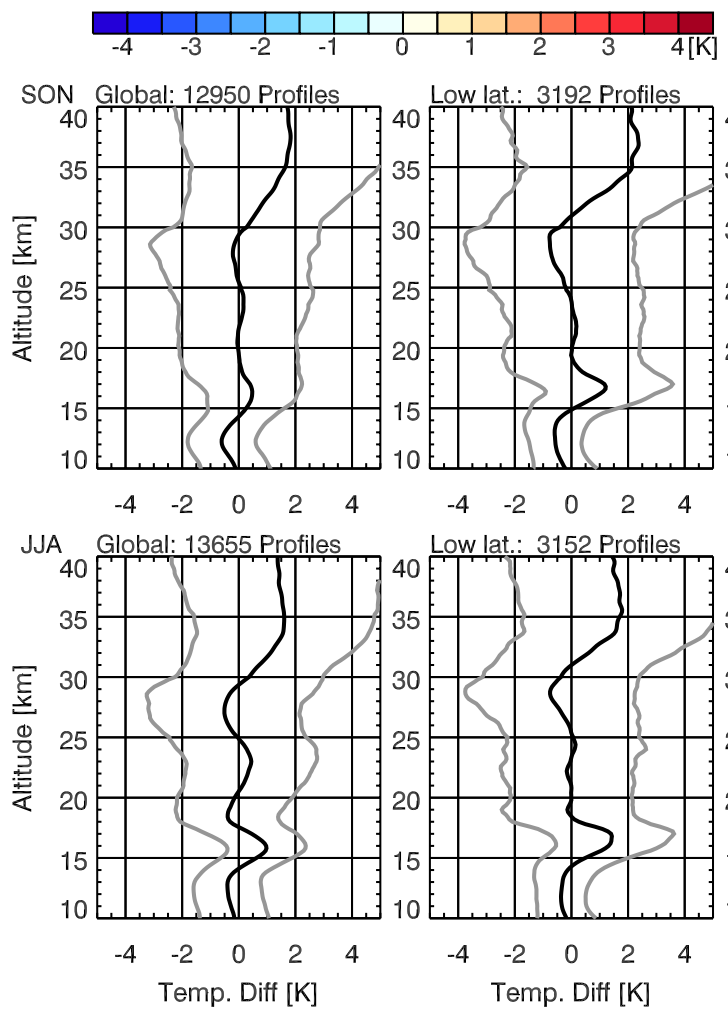

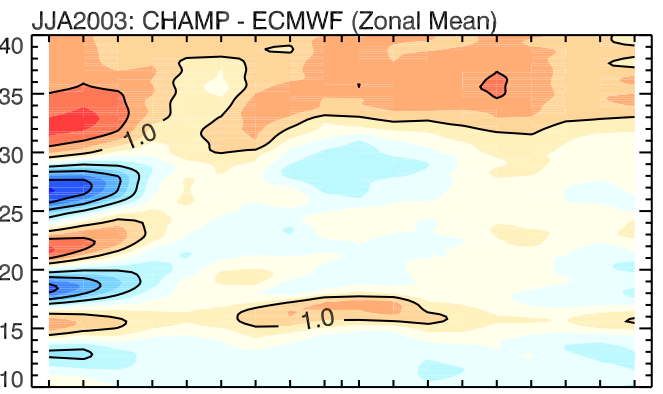

-85-75-65-55-45-35-25-15 -505 1525354555657585 Latitude [deg]
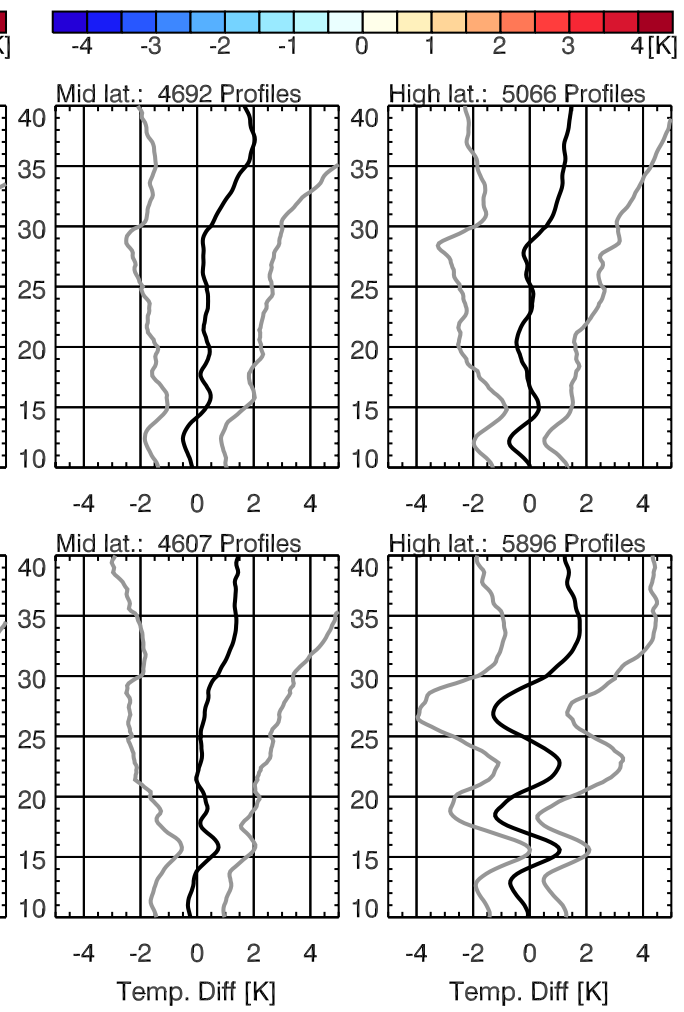

Fig. 6. CCR CHAMP temperature differences relative to ECMWF analyses. Same format as Fig. 2.

The general warm bias above $30 \mathrm{~km}$ is of particular interest here since it demonstrates the relative independency of CCR retrievals from their high-altitude initialisation data, thanks to the careful initialisation approach. CCR shows no warm bias compared to any other correlative dataset except GFZ, which is strictly tied to ECMWF at high altitudes (cf. Sect. 3.3.1). The bias above $30 \mathrm{~km}$ visible in Fig. 6 is thus attributable as cold bias to the ECMWF analyses. Particularly the comparison to MIPAS (Fig. 4) indicates no CCR bias between 30 and $\sim 37 \mathrm{~km}$ (except the JJA polar vortex bias), which in turn indicates that the CCR high-altitude initialisation scheme is insensitive to moderate biases $(\sim 3 \mathrm{~K})$ in the a priori data at least up to $35 \mathrm{~km}$ (a potential residual cold bias above $35 \mathrm{~km}$ is discussed in Sect. 4.5). Comparison to other analyses (see next Sect. 4.5) indicate no warm CCR bias above $30 \mathrm{~km}$ as well.

\subsection{Comparison to other atmospheric analyses}

Figure 7 shows the intercomparison results between CCR CHAMP and four atmospheric analyses (as introduced in Sect. 3.3.3), which allows to cross-check and further assess the consistency of the results found so far. Generally, Fig. 7 indicates that the bias in JJA at southern high latitudes above $30 \mathrm{~km}$ is partly attributable to CCR. It is visible in all JJA 2003 differences except for NCEP Rean which does not reach high enough. Below $30 \mathrm{~km}$, the biases are in general found below $1 \mathrm{~K}$ in most altitudes and latitudes but several exceptions occur: In the MetO, NCEP/CPC, and NCEP Rean comparisons, a cold bias appears near the low latitude tropopause. This can be mainly attributed to the lower vertical resolution of the analyses relative to CCR. In case of NCEP Rean (see Sect. 5) also a further bias plays a role. In 


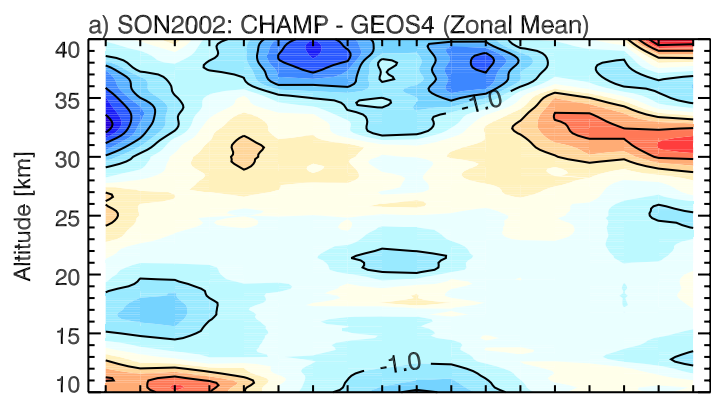

-85-75-65-55-45-35-25-15-505 1525354555657585

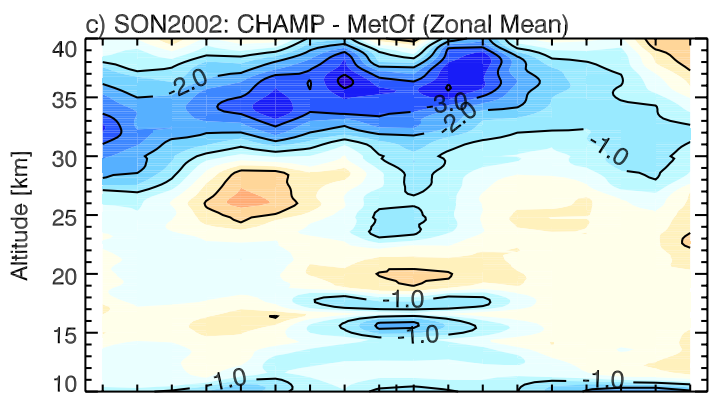

-85-75-65-55-45-35-25-15-505 1525354555657585

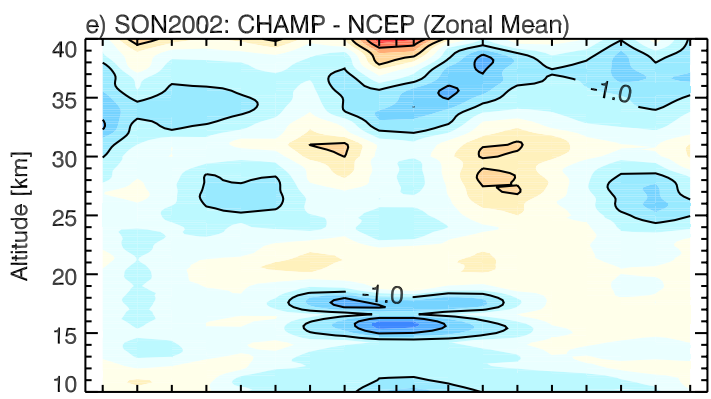

-85-75-65-55-45-35-25-15 -505 1525354555657585

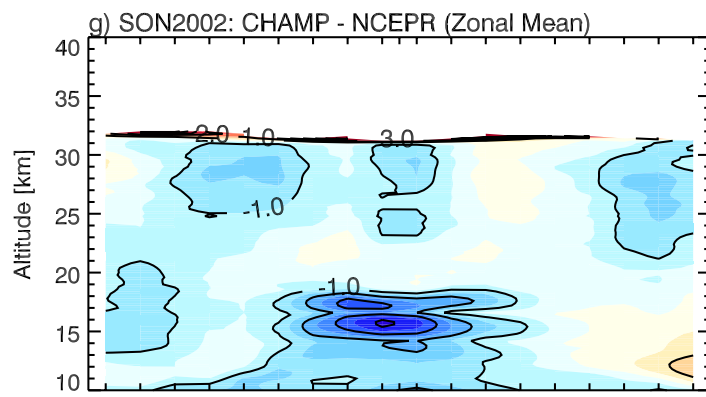

-85-75-65-55-45-35-25-15-505 1525354555657585 Latitude [deg]

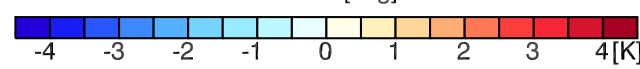

b) JJA2003: CHAMP - GEOS4 (Zonal Mean)

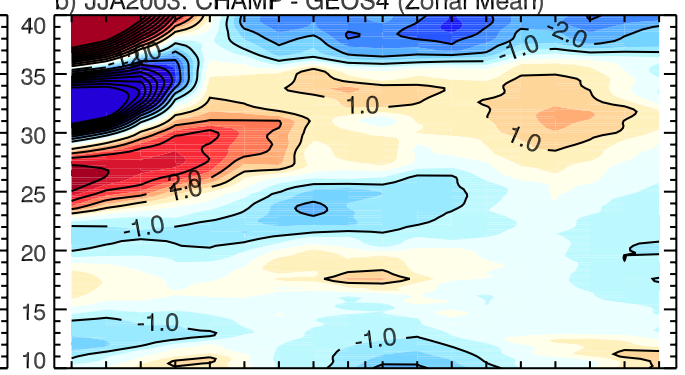

-85-75-65-55-45-35-25-15-505 1525354555657585

d) JJA2003: CHAMP - MetQf (Zonal Mean)

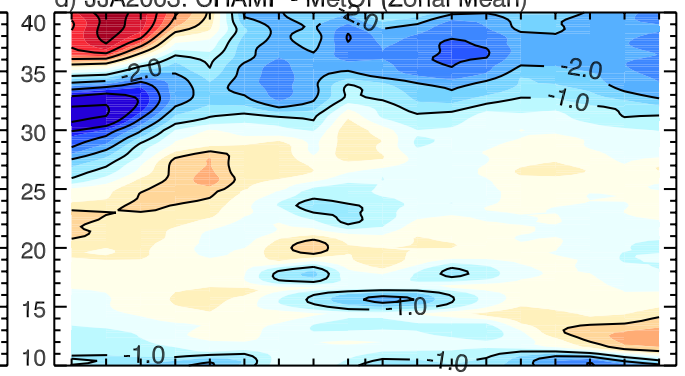

-85-75-65-55-45-35-25-15-505 1525354555657585

f) JJA2003: CHAMP - NCEP (Zonal Mean)

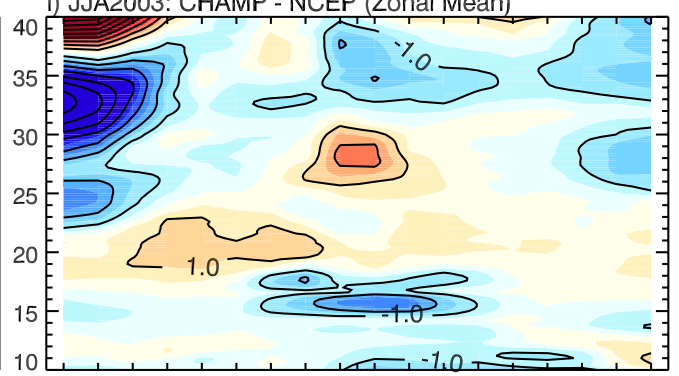

-85-75-65-55-45-35-25-15-505 1525354555657585 h) JJA2003: CHAMP - NCEPR (Zonal Mean)

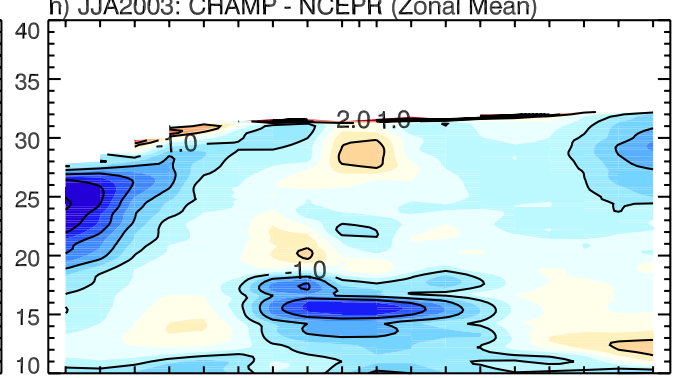

$-85-75-65-55-45-35-25-15-5051525354555657585$ Latitude [deg]

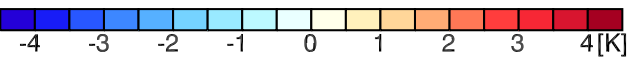

Fig. 7. CCR CHAMP zonal-mean systematic temperature differences (bias) in 18 latitude bands (left column: SON 2002, right column JJA 2003) relative to four meteorological analyses. Top row: GEOS-4 (GEOS4), upper middle row: MetO (MetOf), lower middle row: NCEP/CPC (NCEP), bottom row: NCEP Rean (NECPR).

addition to the tropopause features, there are several severe biases visible (e.g., around $25 \mathrm{~km}$ in GEOS-4), but none of these appear consistently in more than one analysis. This implies that they are related to the specific problems in the different analysis systems and underlines the value of the RO data as reference dataset.

Above about $35 \mathrm{~km}$, a consistent (cold) bias shows up in the GEOS-4, MetO, and to a lesser extent the NCEP/CPC 


\begin{tabular}{|c|c|c|c|c|c|c|c|c|c|c|c|c|c|c|c|c|}
\hline & \multicolumn{2}{|c|}{$\begin{array}{l}\text { CHGFZ } \\
\text { SON JJA }\end{array}$} & \multicolumn{2}{|c|}{\begin{tabular}{|l} 
MIPAS \\
SON JJA
\end{tabular}} & \multicolumn{2}{|c|}{$\begin{array}{l}\text { ECMWF } \\
\text { SON JJA }\end{array}$} & \multicolumn{2}{|c|}{\begin{tabular}{|c|c} 
GEOS-4 \\
SON JJA
\end{tabular}} & \multicolumn{2}{|c|}{\begin{tabular}{|c} 
MetO \\
SON JJA
\end{tabular}} & \multicolumn{2}{|c|}{$\begin{array}{l}\text { NCEP/CPC } \\
\text { SON JJA }\end{array}$} & \multicolumn{2}{|c|}{\begin{tabular}{|l} 
NCEP Rean \\
SON JJA
\end{tabular}} & \multirow{2}{*}{\begin{tabular}{|c|} 
Mean \\
0.1
\end{tabular}} \\
\hline \multirow{6}{*}{$30-40 \mathrm{~km}$} & high $\mathrm{NH}$ & 1.6 & 1.1 & 0.8 & -0.4 & 1.0 & 1.1 & 0.7 & -0.4 & -0.4 & -2.0 & -0.8 & -1.2 & & & \\
\hline & $\operatorname{mid} \mathrm{NH}$ & 2.1 & 1.9 & & d. & 1.4 & 1.5 & 0.4 & -0.4 & -1.2 & -1.6 & -0.4 & -0.3 & & & 0.3 \\
\hline & low $\mathrm{NH}$ & 1.8 & 2.1 & -0.7 & -0.4 & 1.6 & 1.2 & -1.4 & -0.8 & -2.4 & -1.9 & -0.8 & -0.8 & & & -0.2 \\
\hline & low SH & 2.1 & 2.4 & -1.1 & -0.4 & 1.6 & 1.3 & -1.3 & -0.4 & -2.4 & -1.8 & -0.2 & 0.4 & & & -0.1 \\
\hline & mid SH & 1.9 & 1.8 & -0.3 & 0.4 & 1.5 & 1.0 & -0.5 & 0.0 & -2.1 & -1.1 & -0.5 & -0.6 & & & 0.1 \\
\hline & high SH & 1.2 & -1.7 & -0.9 & 1.6 & 1.3 & 1.9 & -1.6 & -0.7 & -1.8 & -0.4 & -0.8 & -1.7 & & & -0.3 \\
\hline \multirow{6}{*}{$20-30 \mathrm{~km}$} & high $\mathrm{NH}$ & -0.2 & -0.2 & 01 & -0.1 & & 0 & -0.2 & -0.3 & 0.0 & -0.0 & -0.6 & -0.6 & -1.2 & -1.2 & -0.3 \\
\hline & $\mathrm{NH}$ & 0.4 & 0.2 & .3 & S.K & 0 & 0 & 2 & K & 0.3 & 0.1 & 0.2 & 0.1 & 0.3 & -0.5 & 0.1 \\
\hline & low $\mathrm{NH}$ & & 0.2 & -1.1 & -0.7 & -0.2 & -0.2 & -0.1 & -0.6 & -0.3 & -0.1 & & 0.7 & -0.4 & -0.2 & -0.2 \\
\hline & low SH & -5.0 & 0.2 & -0.8 & -0.6 & -0.2 & -0.1 & $-\infty .4$ & .0 .4 & v & 8.2 & -6.0 & 0.6 & -0.5 & 5.1 & -0.1 \\
\hline & mid SH & 0.2 & 0.2 & -0.2 & -0.0 & 0.2 & 0.1 & 0.2 & 0.8 & 0.5 & 0.6 & -0.6 & 0.2 & -1.0 & -0.8 & 0.0 \\
\hline & high SH & 0.3 & -0.9 & -0.3 & -0.5 & -0.2 & -0.4 & 0.1 & 1.4 & -0.7 & -0.3 & -0.3 & -1.3 & -0.5 & -2.9 & -0.5 \\
\hline \multirow{6}{*}{$10-20 \mathrm{~km}$} & (g) & & $\infty$ & $-\infty$. & 0.3 & -0.3 & 0.1 & 0.3 & -0.3 & 0.2 & 0.2 & 0.0 & 1 & 0.1 & 0.1 & 0.0 \\
\hline & mid $\mathrm{NH}$ & 0.2 & 0.1 & -0.6 & 0.3 & & 0.1 & -0.2 & -0.2 & $-\infty .0$ & -0.1 & -0.1 & -0.2 & -0.3 & -0.4 & -0.1 \\
\hline & $\mathrm{NH}$ & 20 & ar & -0.3 & -0.5 & & 0.2 & -0.1 & -0.6 & -0.5 & -0.5 & -0.9 & -0.8 & -1.4 & -1.5 & -0.5 \\
\hline & low SH & -0.0 & 0.1 & -0.5 & 0.5 & & 0.3 & -0.5 & -0.1 & -0.5 & -0.3 & -0.9 & -0.5 & -1.7 & -1.6 & -0.4 \\
\hline & high SH & 0.2 & 0.2 & 0.3 & 0.4 & & 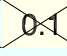 & -0.3 & -0.2 & & & -0.1 & .2 & -0.6 & -0.3 & -0.0 \\
\hline & high SH & 0.3 & 0.0 & 0.7 & & -0.1 & -0.4 & -0.3 & -0.4 & -0.0 & -0.2 & -0.2 & 0.1 & -0.9 & -0.7 & -0.2 \\
\hline 00 & mean & 1.8 & 1.3 & -0.4 & 0.1 & 1.4 & 1.3 & -0.6 & -0.4 & -1.7 & -1.5 & -0.6 & -0.8 & & & -0.0 \\
\hline $20-30$ km & mean & 0.1 & -0.1 & -0.4 & -0.3 & -0.0 & -0.0 & -0.0 & 0.2 & -0.0 & 0.0 & -0.2 & -0.1 & -0.6 & -1.0 & -0.2 \\
\hline $10-20 \mathrm{~km}$ & mean & 0.1 & 0.1 & -0.1 & -0.0 & -0.0 & 0.0 & -0.3 & -0.3 & -0.1 & -0.1 & -0.4 & -0.2 & -0.8 & -0.7 & -0.2 \\
\hline $10-40 \mathrm{~km}$ & mean & 0.7 & 0.4 & -0.3 & -0.1 & 0.5 & 0.4 & -0.3 & -0.2 & -0.6 & -0.5 & -0.4 & -0.4 & -0.7 & -0.8 & -0.1 \\
\hline
\end{tabular}

Fig. 8. CCR CHAMP average temperature differences $[\mathrm{K}]$ relative to the operational CHAMP retrieval results from GFZ (CHGFZ), Envisat MIPAS, ECMWF operational analyses, GEOS-4 analyses, MetO analyses, NCEP/CPC analyses, and NCEP Reanalyses in SON 2002 and JJA 2003 , respectively, at low $\left(0^{\circ}\right.$ to $\left.30^{\circ}\right)$, mid $\left(30^{\circ}\right.$ to $\left.60^{\circ}\right)$, and high $\left(60^{\circ}\right.$ to $\left.90^{\circ}\right)$ latitudes of the northern (NH) and the southern hemisphere (SH) between $10-20 \mathrm{~km}, 20-30 \mathrm{~km}$, and $30-40 \mathrm{~km}$. Aggregate means (averages of the individual comparison means) are also shown (rightmost column and four bottom lines). The colours in each cell visualise the magnitude of a cold (blue) and warm (yellow/red) difference, respectively, crosses indicate statistically insignificant $(<2 \sigma-l e v e l)$ differences/biases. Empty white cells indicate that there was no comparison due to insufficient correlative data.

comparisons. This could be partly a CCR cold bias (though not visible in the comparison to MIPAS), at least above 35 $\mathrm{km}$, which would be reasonable given the upper stratosphere cold bias in the ECMWF analyses serving as initialisation data.

Generally, these comparisons are consistent with and add confidence to the results of the previous sections. Additionally, interesting details about the specific analyses can be derived, for example, the significant cold bias (now viewed relative to CCR) of GEOS- 4 in the JJA 2003 southern high latitudes between about 25 and $30 \mathrm{~km}$ and the strong warm bias of NCEP Rean in about the same region.

\section{Summary and conclusions}

This study described and evaluated the CCR RO processing scheme of the Wegener Center, Univ. of Graz, which partic- ularly aims at delivering bias-free atmospheric profiles for climate monitoring and research. The CCR RO temperature retrievals from CHAMP data of two representative seasons (SON 2002 and JJA 2003) were validated against correlative datasets from operational GFZ Potsdam CHAMP retrievals, Envisat MIPAS and GOMOS temperatures, ECMWF analyses, and four further atmospheric analyses.

Figure 8 provides a summary overview on the validation results of the study in the form of an "error portrait diagram", which shows $10 \mathrm{~km}$-altitude-mean systematic differences (biases) for all comparisons presented and indicates statistically insignificant differences with crosses.

Figure 8 shows that temperatures in the region above $30 \mathrm{~km}$ are strongly varying between the correlative datasets. ECMWF and GFZ are significantly colder than CCR (1.3 to $1.8 \mathrm{~K})$, all other analyses are warmer than CCR $(0.4$ to $1.7 \mathrm{~K})$. MIPAS is closest to CCR, with mean biases below $0.5 \mathrm{~K}$. 
This gives confidence in the CCR temperatures above $30 \mathrm{~km}$, since MIPAS is the only (in a bias-sense) virtually modelindependent correlative dataset in this evaluation study and uses an entirely different measurement principle than CCR. However, a consistent CCR cold bias against three different analyses above $35 \mathrm{~km}$ (Sect. 4.5) is also to be noted. Additionally, it has been found (Sect. 4.4) that an extremely biased a priori (about $10 \mathrm{~K}$ or more) degrades CCR RO temperature accuracy down to $30 \mathrm{~km}$ (JJA southern high latitudes).

Below $30 \mathrm{~km}$, no systematic biases were found for CCR RO. NCEP Rean stands out a little bit being generally warmer than CCR $(\sim 0.7 \mathrm{~K})$, in accordance with Manney et al. (2005a), who concluded that NCEP Rean is not suited for stratospheric studies due to extensive biases. The global mean intercomparison bias (over all correlative datasets, all regions, and both seasons) between $10-20 \mathrm{~km}$ and $20-30 \mathrm{~km}$ amounts to $-0.2 \mathrm{~K}$, whereby half of this biases is caused by NCEP Rean. The following main conclusions can be drawn.

1. In the global mean within $10-30 \mathrm{~km}$ altitude we find that the present validation observationally constrains the potential RO temperature bias to be $<0.2 \mathrm{~K}$. Latitudinally resolved analyses show biases to be observationally constrained to $<0.2-0.5 \mathrm{~K}$ up to $35 \mathrm{~km}$ in most cases and up to $30 \mathrm{~km}$ in any case, even if a severely biased (about $10 \mathrm{~K}$ or more) a priori information is used in the high altitude initialisation of the retrieval.

2. No evidence is found for the 10 to $35 \mathrm{~km}$ altitude range of residual RO bias sources other than potentially propagated downward from initialisation. This indicates that the widely quoted RO promise of "unbiasedness and long-term stability due to intrinsic self-calibration" can indeed be realised given care in the data processing to strictly limit structural uncertainty.

3. Adequate high-altitude initialisation is crucial for accurate stratospheric RO retrievals. Still common methods of initialising, in addition to bending angle initialisation, the hydrostatic integral with an upper boundary temperature or pressure value derived from meteorological analyses, are prone to introduce biases from the initialisation down to below about $25 \mathrm{~km}$.

4. Also above 30 to $35 \mathrm{~km}$ GNSS RO still delivers a considerable amount of observed information up to around $40 \mathrm{~km}$. This is particularly interesting for NWP assimilation systems where direct assimilation of non-initialised (a priori-free) observed RO bending angles appears thus to be the method of choice.

Overall we conclude that the RO method in general, and the Wegener Center CCR scheme based on GFZ Potsdam phase delay and orbital data in particular, is capable of providing high quality and essentially unbiased atmospheric profiles up to about $35 \mathrm{~km}$ with high vertical resolution $(\sim 1 \mathrm{~km})$ and global coverage, adequate for climate monitoring and research.

While this study based on single-satellite CHAMP data clearly underlined the value of RO for climate applica- tions, upcoming data from new missions such as Formosat3/COSMIC (launched in April 2006) and MetOp (launched in October 2006) will strongly further enhance the utility of RO for improved operational monitoring of climate variability and change in the future.

Acknowledgements. We thank J. Wickert and T. Schmidt (GFZ Potsdam, Germany) for cooperation and the provision of CHAMP data, D.-Y. Wang (Univ. of New Brunswick, NB, Canada; formerly IMK Karlsruhe, Germany) for support and advice regarding MIPAS data, ECMWF for access to their operational analysis data, the British Atmospheric Data Centre for MetO data, the GSFC ACD Science Data System for NCEP/CPC data, and NASA's GMAO for GEOS-4 data. NCEP reanalysis data were provided by the NOAA/CIRES Climate Diagnostics Center, Boulder, CO. Work at the Jet Propulsion Laboratory, CalTech, CA, was done under contract with the National Aeronautics and Space Administration. A. Gobiet received funding for the work from the START research award of G. Kirchengast funded by the Austrian Ministry for Education, Science, and Culture and managed under Program Y103-N03 of the Austrian Science Fund (FWF). M. Borsche received funding from the Austrian Aeronautics and Space Agency (FFG-ALR) via the CHAMPCLIM project.

Edited by: R. Cohen

\section{References}

Alfred, J., Fromm, M., Bevilacqua, R., Nedoluha, G., Strawa, A., Poole, L., and Wickert, J.: Observations and analysis of polar stratospheric clouds detected by POAM III and SAGE III during the SOLVE II/VINTERSOL campaign in the 2002/2003 Northern Hemisphere winter, Atmos. Chem. Phys., 7, 2151-2163, 2007 ,

http://www.atmos-chem-phys.net/7/2151/2007/.

Bertaux, J. L., Megie, G., Widemann, T., Chassefiere, E., Pellinen, R., Kyrölä, E., Korpela, S., and Simon, P.: Monitoring of ozone trends by stellar occultations: the GOMOS instrument, Adv. Sapce. Res., 11, 237-242, 1991.

Bevis, M., Businger, S., Herring, T. A., Rocken, C., Anthes, R. A., and Ware, R. H.: GPS meteorology: Mapping zenith wet delays onto precipitable water, J. Appl. Met., 33, 379-386, 1994.

Bloom, S. C., da Silva, A. M., Dee, D. P., et al.: The Goddard Earth Observing Data Assimilation System, GEOS DAS Version 4.0.3: documentation and validation, Technical Report No. 104606 V26, NASA, 2005.

Borsche, M., Kirchengast, G., and Foelsche, U.: Tropical tropopause climatology as observed with radio occultation measurements from CHAMP compared to ECMWF and NCEP Analyses, Geophys. Res. Lett., 34, L03702, doi:10.1029/2006GL027918, 2007.

ECMWF: IFS documentation CY28r1, ECMWF, Reading, UK, 2004.

European Space Agency: Envisat, MIPAS An instrument for atmospheric chemistry and climate research, ESA Publications Division, SP-1229, ESTEC, Noordwijk, The Netherlands, 2000.

Fischer, H. and Oelhaf, H.: Remote sensing of vertical profiles of atmospheric trace constituents with MIPAS limb-emission spectrometers, Appl. Opt., 35, 2787-2796, 1996. 
Fjeldbo, G. F., Eshleman, V. R., and Kliore, A. J.: The neutral atmosphere of Venus as studied with the Mariner V radio occultation experiments, Astron. J., 76, 123-140, 1971.

Foelsche, U., Gobiet, A., Loescher, A., Kirchengast, G., Steiner, A. K., Wickert, J., and Schmidt, T.: The CHAMPCLIM Project: An overview, in: Earth Observation with CHAMP: Results from Three Years in Orbit, edited by: Reigber, C., Luehr, H., Schwintzer, P., and Wickert, J., Springer, Berlin Heidelberg, 615-619, 2005.

Foelsche, U., Gobiet, A., Steiner, A. K., Kirchengast, G., Borsche, M., Schmidt, T., and Wickert, J.: Global Climatologies Based on Radio Occultation Data: The CHAMPCLIM Project, in: Atmosphere and Climate: Studies by Occultation Methods, edited by: Foelsche, U., Kirchengast, G., and Steiner, A. K., Springer, Berlin Heidelberg, 303-314, 2006.

Gobiet, A. and Kirchengast, G.: Advancements of GNSS Radio Occultation Retrieval in the Upper Stratosphere for Optimal Climate Monitoring Utility, J. Geophys. Res., 109, D24110, doi:10.1029/2004JD005117, 2004.

Gobiet, A., Foelsche, U., Steiner, A. K., Borsche, M., Kirchengast, G., and Wickert, J.: Climatological validation of stratospheric temperatures in ECMWF operational analyses with CHAMP radio occultation data, Geophys. Res. Lett., 32, L12806, doi:10.1029/2005GL022617, 2005.

Gobiet, A.: Radio occultation data analysis for climate monitoring and first climatologies from CHAMP (PhD thesis), Scientific Report No. 6-2005, 140 pp, Wegener Center Verlag, University of Graz, Austria, 2005.

Goody, R., Anderson, J., and North, G.: Testing climate models: an approach, Bull. Am. Met. Soc., 79, 2541-2549, 1998.

GRAS-SAG: The GRAS instrument on MetOp, ESA/EUMETSAT Rep. (ESA No. VR/3021/PI, EUMETSAT No. EPS/MIS/IN/9), ESA/ESTEC, Noordwijk, Netherlands, 1998.

Hajj, G. A., Kursinski, E. R., Romans, L. J., Bertinger, W. I., and Leroy, S. S.: A technical description of atmospheric sounding by GPS occultation, J. Atmos. Sol.-Terr. Phy., 64, 451-469, 2002.

Hajj, G. A., Ao, C. O., Iijima, P. A., Kuang, D., Kursinski, E. R., Mannuchi, A. J., Meehan, T. K., Romans, L. J., de al Torre Juarez, M., and Yunck, T. P.: CHAMP and SAC-C atmospheric occultation results and intercomparisons, J. Geophys. Res., 109, D05109, doi:10,1029/2003JD003909, 2004.

Healy, S. B. and Eyre, J. R.: Retrieving temperature, water vapour and surface pressure information from refractive index profiles derived by radio occultation: A simulation study, Q. J. R. Meteorol. Soc., 126, 1661-1683, 2000.

Healy, S. B.: Smoothing radio occultation bending angles above 40 km, Ann. Geophys., 19, 459-468, 2001, http://www.ann-geophys.net/19/459/2001/.

Healy, S. B., Jupp, A. M., and Marquardt, C.: Forecast impact experiment with GPS radio occultation measurements, Geophys. Res. Lett., 32, L03804, doi:10.1029/2004GL020806, 2005.

Healy, S. B. and Thépaut, J.-N.: Assimilation experiments with CHAMP GPS radio occultation measurements, Q. J. R. Meteorol. Soc., 132, 605-623, doi:10.1256/qj.04.182, 2006.

Hedin, A. E.: Extension of the MSIS thermosphere model into the middle and lower atmosphere, J. Geophys. Res., 96, 1159-1172, 1991.

Hocke, K., Igarashi, K., and Tsuda, T.: High-resolution profiling of layered structures in the lower stratosphere by GPS occultation,
Geophys. Res. Lett., 30(8), 1426, doi:10.1029/2002GL016566, 2003.

Kursinski, E. R., Hajj, G. A., Schofield, J. T., Linfield, R. P., and Hardy, K. R.: Observing Earth's Atmosphere with Radio Occultation Measurements Using the Global Positioning System, J. Geophys. Res., 102, 23 429-23 465, 1997.

Kyrölä, E., Tamminen, J., Leppelmeier, G. W., et al.: GOMOS on Envisat: An overview, Adv. Space Res., 33, 1020-1028, 2004.

Leroy, S. S., Dykema, J. A., and Anderson, J. G.: Climate Benchmarking Using GNSS Occultation, in: Atmosphere and Climate: Studies by Occultation Methods, edited by: Foelsche, U., Kirchengast, G., and Steiner, A. K., Springer, Berlin-Heidelberg, pp 287-301, 2006.

Loiselet, M., Stricker, N., Menard, Y., and Luntama, J.-P.: GRAS - MetOp's GPS-based atmospheric sounder, ESA Bulletin 102, 38-44, 2000.

Manney, G. L., Allen, D. M., Krüger, K., Naujokat, B., Santee, M. L., Sabutis, J. L., Pawson, S., Swinbank, R., Randall, C. E., Simmons, A. J., and Long, C.: Diagnostic comparison of meteorological analyses during the 2002 antarctic winter, Mon. Weather Rev., 133, 1261-1278, 2005a.

Manney, G. L., Krüger, K., Sabutis, J. L., Sena, S. A, and Pawson, S.: The remarkable 2003-2004 winter and other recent warm winters in the Arctic stratosphere since the late 1990s, J. Geophys. Res., 110, D04107, doi:10.1029/2004JD005367, 2005b.

Marquardt, C., Schöllhammer, K., Beyerle, G., Schmidt, T., Wickert, J., and Reigber, C.: Validation and data quality of CHAMP radio occultation data, in: First CHAMP Mission Results, edited by: Reigber, C., Lühr, H., and Schwintzer, P., Springer, BerlinHeidelberg-New York, 384-396, 2003.

Retscher, C., Gobiet, A., and Kirchengast, G.: Stratospheric temperature and ozone sounding with ENVISAT/GOMOS stellar occultation, in: Occultation for Probing Atmosphere and Climate, edited by: Kirchengast, G., Foelsche, U., and Steiner, A. K., Springer, Berlin-Heidelberg-New York, 299-308, 2004.

Retscher, C., Kirchengast, G., and Gobiet, A.: Stratospheric temperature sounding with Envisat/GOMOS by exploitation of SFA/SATU data, in: Atmosphere and Climate: Studies by Occultation Methods, edited by: Kirchengast, G., Foelsche, U., and Steiner, A. K., Springer, Berlin-Heidelberg-New York, 55-66, 2006.

Rocken, C., Kuo, Y., Schreiner, W. S., Hunt, D., Sokolovskij, S., and McCormick, C.: COSMIC System Description, Terr. Atmos. Ocean. Sci., 11, 21-52, 2000.

Rodgers, C. D. and Connor, B. J.: Intercomparison of remote sensing Instruments, J. Geophys. Res., 108(D3), 4116, doi:10.1029/2002JD002299, 2003.

Schreoder, T., Leroy, S., Stendel, M., and Kaas, E.: Validating the microwave sounding unit stratospheric record using GPS occultation, Geophys. Res. Lett., 30(14), 1734, doi:10.1029/2003GL017588, 2003.

Sokolovskiy, S. and Hunt, D.: Statistical optimization approach for GPS/Met data inversions, Paper presented at URSI GPS/Met Workshop, Tucson, Arizona, 1996.

Steiner, A. K., Kirchengast, G., and Ladreiter, H. P.: Inversion, error analysis, and validation of GPS/MET occultation data, Ann. Geophys., 17, 122-138, 1999, http://www.ann-geophys.net/17/122/1999/.

Steiner, A. K., Gobiet, A., Foelsche, U., and Kirchengast, G.: Radio 
occultation data processing advancements for optimizing climate utility, Tech. Report for ASA No. 3/2004, Inst. for Geophys., Astrophys. and Meteorol., Univ. of Graz, Austria, 2004.

Steiner, A. K. and Kirchengast, G.: Error analysis for GNSS radio occultation data based on ensembles of profiles from end-to-end simulations, J. Geophys. Res., 110, D15307, doi:10.1029/2004JD005251, 2005.

Swinbank, R., Ingleby, N. B., Boorman, P. M., and Renshaw, R. J.: A 3D variational data assimilation system for the stratosphere and troposphere, Met Office Numerical Weather Prediction Forecasting Research Scientific Paper, 71, UK Met Office, 2002.

Syndergaard, S.: Modeling the impact of Earth's oblateness on the retrieval of temperature and pressure profiles from limb sounding, J. Atmos. Sol.-Terr. Phys., 60(2), 171-180, 1998.

Syndergaard, S.: Retrieval analysis and methodologies in atmospheric limb sounding using the GNSS radio occultation technique, DMI Sci. Rep., 99-6, Danish Met. Inst., Copenhagen, Denmark, 1999.

Rieder, M. and Kirchengast, G.: Error analysis and characterization of atmospheric profiles retrieved from GNSS occultation data, J. Geophys. Res., 106(D23), 31 755-31 770, 2001.

von Clarmann, T. and Grabowski, U.: Elimination of hidden a priori information from remotely sensed profile data, Atmos. Chem. Phys., 7, 397-408, 2007, http://www.atmos-chem-phys.net/7/397/2007/.

von Clarmann, T., Glatthor, N., Grabowski, U., et al.: Retrieval of temperature and tangent altitude pointing from limb emission spectra recorded from space by the Michelson Interferometer for Passive Atmospheric Sounding (MIPAS), J. Geophys. Res., 108(D23), 4736, doi:10.1029/2003JD003602, $2003 \mathrm{a}$.

von Clarmann, T., Ceccherini, S., Doicu, A., et al.: A blind test retrieval experiment for infrared limb emission spectrometry, J. Geophys. Res., 108(D23), 4746, doi:10.1029/2003JD003835, 2003 b. von Engeln, A.: A first test of climate monitoring with radio occultation instruments: Comparing two processing centers, Geophys. Res. Lett., 33, L22705, doi:10.1029/2006GL027767, 2006.

Vorob'ev, V. V. and Krasnil'nikova, T. G.: Estimation of the accuracy of the atmospheric refractive index recovery from Doppler shift measurements at frequencies used in the NAVSTAR system, Phys. Atmos. Ocean, 29, 602-609, 1994.

Wang, D.-Y., Stiller, G. P., von Clarmann, T., et al.: Crossvalidation of MIPAS/ENVISAT and GPS-RO/CHAMP temperature profiles, J. Geophys. Res., 109, D19311, doi:10.1029/2004JD004963, 2004.

Wang, D.-Y., von Clarmann, T., Fischer, H., et al.: Validation of stratospheric temperatures measured by Michelson Interferometer for Passive Atmospheric Sounding (MIPAS) on Envisat, J. Geophys. Res., 110, D08301, doi:10.1029/2004JD005342, 2005.

Wickert, J.: Interactive comment on "Retrieval of temperature profiles from CHAMP for climate monitoring: intercomparison with Envisat MIPAS and GOMOS and different atmospheric analyses" by A. Gobiet et al., Atmos. Chem. Phys. Discuss., 7, S330S332, 2007.

Wickert, J., Reigber, C., Beyerle, G., König, R., Marquardt, C., Schmidt, T., Grunwaldt, L., Galas, R., Meehan, T., Melbourne, W., and Hocke, K.: Atmosphere sounding by GPS radio occultation: First results from CHAMP, Geophys. Res. Lett., 28, 32633266, 2001.

Wickert, J., Schmidt, T., Beyerle, G., König, R., Reigber, C., and Jakowski, N.: The radio occultation experiment aboard CHAMP: Operational data analysis and validation of vertical atmospheric profiles, J. Met. Soc. Japan, 82, 381-395, 2004.

Wu, B.-H., Chu, V., Chen, P., and King, T.: FORMOSAT3/COSMIC science mission update, GPS Solutions, 9, 111-121, doi:10.1007/s10291-005-0140-z, 2005. 